\title{
Migration, Labor Tasks and Production Structure*
}

\author{
Giuseppe De Arcangelis ${ }^{\dagger}$ Edoardo Di Porto ${ }^{\ddagger}$ Gianluca Santoni ${ }^{\S}$
}

May 2015

\begin{abstract}
We assess the effect of migrants' stock on the production structure of the Italian provinces (NUTS3) in 1995-2006. Although the investigated time span is very short, the effect is small but statistically significant: a doubling in the ratio of foreign-born residents to the province population induces a significant increase in manufactures' value added with respect to services' value added between 12 and 21 per cent. These effects are more intense when considering an increase in foreign-born populations drawn from countries more different to Italy (in terms of GDP per capita and educational attainment).

These results are compatible with the reduced form of a two-sector model where we assume that production is performed with one mobile factor and two sector-specific CES labor composites of simple and complex tasks. If migrants and natives have different productivity when performing simple or complex tasks, an inflow of migrants induces production restructuring in favor of the simple-task intensive sector.
\end{abstract}

Keywords: Rybczynski Effect, International Migration, Province Labor Markets, Specific Factor Model, Productive Tasks.

JEL Classification Codes: F22, C25.

${ }^{*}$ We would like to thank Carlo Altomonte, Giulia Bettin, Paolo Giordani, Hubert Jayet, Fabio Mariani, Paolo Naticchioni, Peter Neary, Gianmarco Ottaviano, Diego Puga, Cristina Tealdi and participants at the ITSG Ancona 2013, at the 4th International Conference on the Economics of Global Interactions (Bari, Italy), at the workshop "Production, R\&D and Knowledge Offshoring: Economic Analyses and Policy Implications" and at seminars we held at Sapienza University of Rome, Bari University, EIEF for useful discussions on earlier versions of this work. We would like to thank also two anonymous referees for the useful suggestions we obtained with respect to previous versions of this work. A special thank goes to the research partnership between ISFOL and the Dipartimento di Scienze Sociali ed Economiche (Sapienza University of Rome) through which we could obtain the data on wages at the detailed sectoral and province level for some robustness tests. A previous version of this paper circulated with the title "Migration, Production Structure and Exports". We kindly acknowledge financial support from Sapienza University of Rome (Ateneo Grant). The authors declare that they have no relevant or material financial interests that relate to the research described in this paper. The usual disclaimers apply.

${ }^{\dagger}$ Dipartimento di Scienze Sociali ed Economiche, Sapienza University of Rome; e-mail: giuseppe.dearcangelis@uniroma1.it.

${ }^{\ddagger}$ CSEF, University of Naples Federico II and UCFS, Uppsala University; e-mail: edoardo.diporto@unina.it.

${ }^{\S}$ CEPII; e-mail: gianluca.santoni@cepii.fr. 


\section{Introduction}

In the last decades industrialized economies in North America and in Europe (Continental and UK) have been the destination of many migrants coming from neighbor countries - like Mexico for the US, or North Africa and Eastern Europe for the European Union (EU) - and from more distant origins - for instance, China and South-East Asia.

The incidence of foreign-born population on natives has almost doubled on average starting in 1990 (not counting undocumented migration), but with many different patterns among the various destination countries.

When investigating the effects on the receivers, economists have highly exploited the regional dimension in order to deal mainly with labor market issues (see Okkerse, 2008, for a recent review).

The debate has focussed intensively on the reaction of wages and natives' unemployment rates when the labor force increases due to immigration. In the US a great deal of studies focuses on the low-educated segment of the labor market, which is the one that may be affected the most $]^{1}$ In Europe the effect is even more mitigated..$^{2}$

Our work focuses on another issue, that is the effect of immigration on the production structure in terms of sectorial recomposition as a byproduct of the effect on regional labor markets.

We borrow from the intuition of traditional theories of international trade, where immigration can be considered as an increase in one of the factor endowments in a multi-sector (or, simply, two-sector) model that can give rise to different adjustments on the production structure, besides the effect on factor prices. The most relevant ones are the changes in production techniques or, alternatively, the changes in the production mix, also known as the Rybczynski effect 3

\footnotetext{
${ }^{1}$ Among the many articles on the subject, Borjas (2003) and Borjas and Katz (2007) found a significative effect on US wages, whereas Card (2007) does not confirm this finding. Ottaviano and Peri (2012) challenge the traditional approach by pointing at the imperfect substitution between natives and migrants in the detailed and fine segments (or cells) of the labor market.

${ }^{2}$ See D'Amuri and Peri (2011) and D'Amuri and Peri (2012). They considered all segments of the European labor markets and not only the low-educated one, as mainly investigated in the US.

${ }^{3}$ Recently, Romalis (2004) obtains the Rybczynski result in a revised Heckscher-Ohlin model.
} 
The main contribution of this paper is empirical. However, we also show that the estimated reduced form can be derived from a theoretical framework that is an extension of the onesector models recently used in this literature (see Peri and Sparber, 2009, and D'Amuri and Peri, 2012).

More precisely, we relate to the recent literature in tasks and offshoring (see, for instance, Grossman and Rossi-Hansberg, 2008) that highlights the importance of labor services (or tasks) when considering the labor market. As natives and foreign-born are assumed to have different relative productivity in performing simple versus complex tasks, immigration is a comparative statics exercise that changes the relative endowment of the economy in terms of labor services and requires a change in the production structure under some given conditions.

Previous studies have investigated the change in factor endowments implied by immigration and have considered two possible effects when wages are not affected, as in our case.

First, migration may induce firms to switch to techniques that are more complementary to the characteristics of the new labor force. For instance, Hanson and Slaughter (2002) considered the local effect in the US states between 1980 and 1990, whereas Gandal et al. (2004) analyzed the particular case of the sudden inflow of migrants from the former Soviet Union in Israel in 1990. Although the two cases are different in terms of types of immigration - typically low-skilled Mexicans in the former case, but high-skilled Russians in the latter the authors conclude for a more relevant role of the changes in production techniques rather than the change in the production mix $4^{4}$ Along the same line, Lewis (2004) analyzed the large inflow of Cuban migrants in Miami through the Mariel boatlift and reached similar conclusions on the rate of technology adoption (i.e., towards less computer-based techniques in Miami with respect to similar cities in the US) rather than an effect in the industry mix.

Recent studies also emphasize the type of change in production techniques; in particular, whether there is an increase or a decrease in the capital-to-labor ratio. Accetturo et al. (2012) conclude for an increase in the ratio when using Italian manufacturing data at the firm level,

\footnotetext{
${ }^{4}$ They relate their results to the debate on skill-biased technological change in the US, or imported skillbiased technological change in the case of Israel.
} 
whereas Lewis (2011) finds a tendency to slow the adoption of automated techniques in US metropolitan areas where migration has been more intense.

Second, immigration may cause an effect in the production structure, but at a highly disaggregated level. Card and Lewis (2007) and Card (2007) find effects on the production structure, but claim that this occurs within sectors (or within firms) rather than between sectors. Bettin et al. (2012) find evidence of production recomposition in favor of low-skilled manufacturing when using firm-level data for the case of Italy, but only for the years 2001-2003.

More recent work has focused on the the composition of the labor force, which generally implies that migration increases the ratio of low-skilled to high-skilled workers.5 As recalled above, most contributions, like Peri and Sparber (2009) or D'Amuri and Peri (2014), are more interested in the effect of migration in the relative wage and use a one-sector model as a reference. D'Amuri and Pinotti (2010) use a similar framework to ours in order to address the effect of migration on female labor supply.

Besides the US and overall Europe, there have been recent studies on other specific countries. González and Ortega (2011) consider the case of Spain, which has some similarities to the Italian case because of the rapid and intense inflow of immigrants (from $4.8 \%$ to $10.8 \%$ of the population between 2001 and 2006). They find that the adjustment has occurred mainly in production techniques with firms located in the high-immigration regions employing relatively more unskilled labor than firms located in similar low-migration regions. Dustmann and Glitz (2014) analyze the case of Germany with firm-level data and distinguish the effects of migration depending on whether we consider a traded or a nontraded sector. In the latter case, they find an effect on factor prices, whereas in traded sectors the adjustment occurs on both the output mix and the change in techniques, but mainly through the latter with firms taking advantage of the greater availability of low-skilled labor. The other important contribution by Dustmann and Glitz (2014) is the effect on the dynamics of entry and exit of heterogeneous firms as a consequence of the labor supply shock caused by immigration.

\footnotetext{
${ }^{5}$ The excellent survey in Lewis (2013) shows the mathematical conditions required in the production function to marginalize the effect on capital and concentrate on the ratio low- to high-skilled labor as emphasized in the recent literature, e.g. Ottaviano and Peri (2012).
} 
The contribution of this paper is twofold.

First, we propose a two-sector version of the task-based model initially proposed by Peri and Sparber (2009) that resembles the traditional sector-specific model of international trade - see Jones (1971), or Feenstra (2004, p.72).

Similarly to Peri and Sparber (2009), migrants are relatively more productive when performing simple tasks; therefore, since they are willing to supply relatively more simple than complex tasks, the inflow of new migrants causes an increase in the relative supply of simple labor services in the overall economy.

Differently from Peri and Sparber (2009), since we assume that output prices are given, the relative wage of complex-to-simple tasks is given. This assumption implies a completely different way of closing the model: the equilibrium is established with the compatible weight of the two sectors in determining a total weighted sum of relative demand for tasks and no longer by the relative wage. Hence, the inflow of new migrants causes an adjustment in the production structure in favor to the simple-task intensive sector rather than on the relative wage of simple-to-complex tasks.

Second, we use Italian provincial data to test for the effect on the production structure of immigration stock changes, which is compatible with the reduced form of our theoretical framework. More precisely, we used the data on foreign-born work permits at the provincial level (NUTS3) starting in the mid-1990s - i.e. the years where the migration presence has become more relevant for the Italian economy - in order to estimate production-composition changes that, we expect, are in favor of manufacturing plus construction (i.e. the relative simple-task intensive aggregate sector) with respect to a subset of services (i.e. the relative complex-task intensive sector).

Many other studies have used regional data within the same country in order to evaluate the effect of migration on wages and some concerns have been raised about the use of regional data following the remark by Borjas et al. (1996), i.e. the fact that the use of regional data may show an attenuated variation due to a dominant national effect. This concern is less important in our case where the production structure can vary substantially among the regions of the 
same country.

We highlight that, among the receiving developed countries, Italy stands out as an interesting setting. Immigration has been very rapid, notwithstanding the absence of colonial ties with the origin countries. From 1995 to 2006 (our sample period) immigration in Italy has increased by a factor of three. Moreover, the immigration has been very diverse in terms of origin countries and both our theoretical framework and empirical model will take account of these characteristics.

Our main empirical findings are encouraging and bring to two main conclusions.

First, an increase in immigration rates (i.e. percentage of foreign-born residents on the total population of the province) raises the relative weight of the simple-task intensive sector, identified as manufacturing and construction. In terms of value added, a doubling of foreignborn presence in percentage terms causes an increase in the value added of manufacturing and construction relative to services between 11 and 21 percent depending on the specification.

We ought to notice that, notwithstanding the time span is quite short to observe changes in the production structure, our results are all significant, though not very large in magnitude.

Second, all migrants are not the same and their productivity may not be that different when considering foreign-born individuals who are more similar to natives. We exploited the large variety in the origins of the immigrants who arrived in Italy in the last two decades and considered the country of origin as a possible indicator of this difference - in terms of GDP per capita or in terms of percentage of migrants in Italy with primary, secondary or third educational degree.

When dividing countries in terciles - low, medium and high GDP per-capita origin countries, or origin countries with a prevalence of migrant in Italy with primary, secondary or tertiary education - our results are confirmed. Indeed, the increase in relative value added of the simple-task intensive sector is still significant and stronger when considering only more diverse migrants (i.e. coming from low-income countries or mainly low-educated).

A typical well-known problem when searching for the effect of migration to the production structure, as well as on wages, is the possible reverse causality. Our model makes no exception. 
In our case we opted for an overidentified two-stage least squares (2SLS) estimation with two instrumental variables - one based on a gravity approach similar to Ortega and Peri (2014) and another one exploiting the effects of the amnesties that occurred in our sample period. We refer to Sections 5 and 6 for a thorough discussion on the validity of our instruments.

Finally, we ought to notice that our analysis must consider widely-defined sectors and cannot be much finer since we exploit the rich geographical/spatial dimension of Italian data on migration. As shown in Section 2, the distribution of migrants is not strikingly different from natives at this high level of aggregation. Hence, our conclusions provide a macro evidence that the desirable (but currently unavailable) micro data with the same time frequency could validate in future analysis.

The remaining sections of the paper are organized as follows. In the Section 2 we present some characteristics of the immigration into Italy by pointing out why this is an interesting setting to study the effect of migration on the production structure. Moreover, we provide some new evidence on the task content of the sectorial dichotomy between simple-task and complex-task intensive sectors. The theoretical framework is illustrated in Section 3 where we derive the comparative statics for the increase in the foreign-born population. The data we use are discussed in Section 4, whereas Sections 5 and 6 present respectively the econometric issues related to our estimation and the empirical results with some robustness checks. Section 7 concludes with a discussion on the interpretation of the results. Three appendices illustrate the derivation of the task content of sectors, an extension of the theoretical model and some robustness checks for the empirical part.

\section{Italy: An Interesting Setting for the Empirical Anal- ysis of Migration}

Italy has been known for many decades as a departure rather than a destination country. Indeed, Italian emigration has been one of the most massive in history, especially before the First World War (in 1913 the emigration rate was 18,7 per 1,000 residents), and continued quite 
intensively till the beginning of the 1970s. In the mid-Seventies the emigration rate drastically decreased, net immigration rates became positive although very small till the beginning of the 1990s when the phenomenon picked up.

Migration in Italy has been characterized by two relevant facts. First, it has been a very rapid phenomenon. Second, due to absence of strong colonial links, migration into Italy has been highly diversified in terms of origin countries, more than in any other European country (currently 189 nationalities are present on the Italian territory).

Non-native presence has tripled in slightly more than a decade. Foreign-born individuals increased from 1.4 million in 2002 to 4.4 million in 2013, which equals $7.4 \%$ of the Italian population $(2.3 \%$ in 2002$)$.

Figure 1 reports the rising stock of foreign-born presence in 1995-2006 as measured by the number of residence permits, which are the data we use in this paper.

The increase is not smooth and the sudden changes are due to the effects of three main amnesties that occurred during the period 1995-2006. The amnesties came together with new migration laws: (a) a first amnesty occurred in 1992 after the first relevant change in the immigration law (citizenship requirements were also extended to 10 years of residence from the original 5 years); around 250 thousands regularized migrants; (b) the second amnesty occurred in 1998 with the introduction of a new migration law (so called Turco-Napolitano law); migrant's residence permits were not strictly linked to labor contracts and expulsions with deportation of the illegal migrants back to their origin country were excluded (unless there were bilateral agreements, as in the case of Albania); around 200 thousand regularized migrants; (c) the third amnesty occurred in 2002 together with a stricter law (the Bossi-Fini law), which required the pre-existence of a labor contract to enter and stay in the country; around 640 thousand regularized migrants.6

When investigating more thoroughly this rapid increase in foreign presence, two characteristics ought to be noticed: first, the quick change in the wide composition of migration by country of origin; second, the uneven geographical localization.

\footnotetext{
${ }^{6}$ The jumps in the time series that occurred around the amnesties end up being very informative and useful for the construction of an instrumental variable (see Section 5 ).
} 


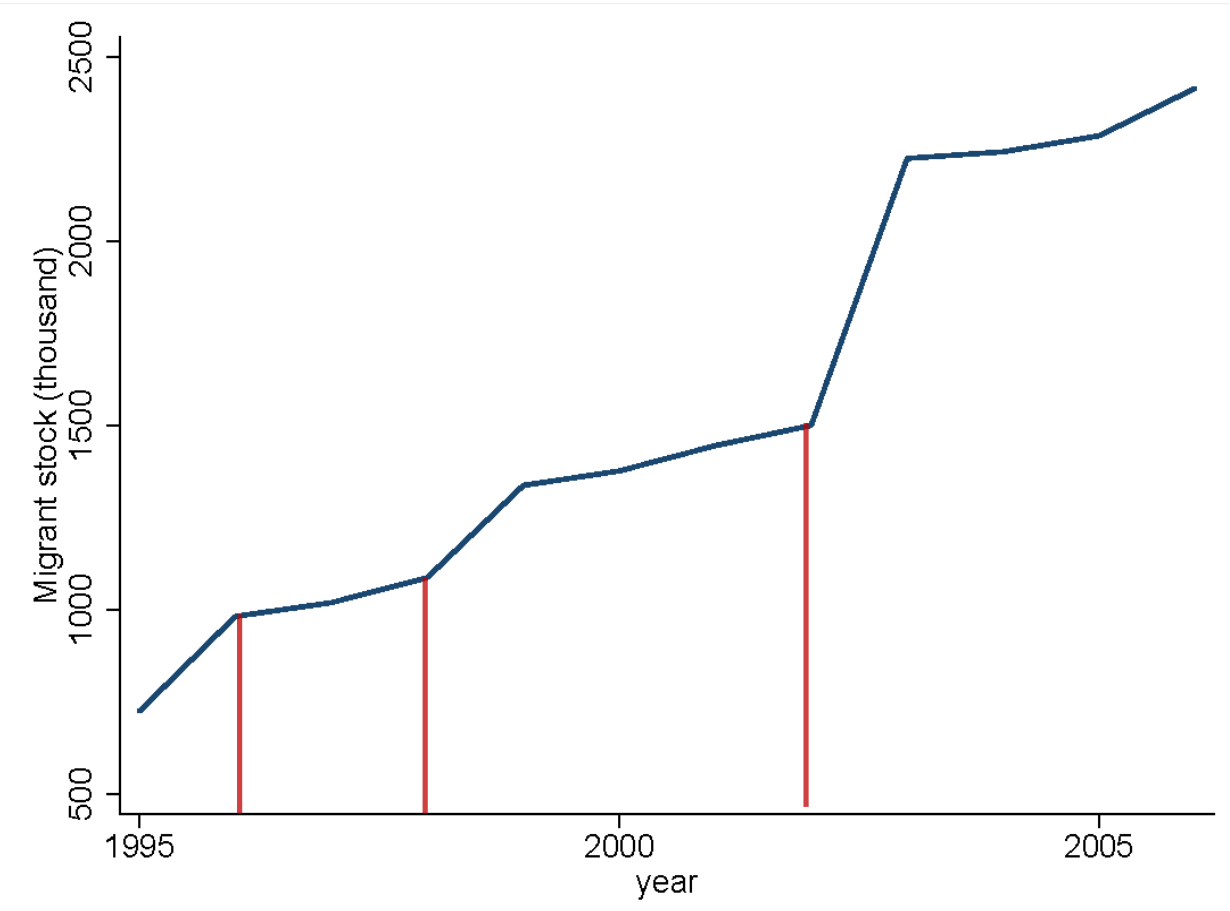

Figure 1: The Stock of Residence Permits in Italy 1995-2006 (Source: Italian Ministry of the Interior and ISTAT).

Regarding the origin, in 1995 most migrants were coming from richer countries, whereas in 2006 the stock composition completely changed. Figure 2a reports the composition of migrants by ranking countries of origin with GDP per capita (in year 1995), more prcisely, by grouping countries in terms of terciles of GDP per-capita.

Figure 2b shows that the 1995 distribution is slightly skewed towards richer origin countries: $1 / 3$ of the migrants were arriving from economies with high per-capita GDP, which was bigger than the percentage for origins from low per-capita GDP. This picture is reversed starting in 2000 and even more drastically in 2006. In 2006 over 90\% of foreigners with regular residence permits in Italy were born in countries with less than 8,000 US\$ per capita.

The second important characteristic is the geographical uneven distribution of migrants in Italy. Migrants tend to settle down where pull factors - like favorable conditions of the labor market, availability of public services, network linkages with previous migrants of the same or similar nationalities - are stronger. From this point of view, the dual characteristic of the Italian economy explains very well why the overall majority of migrants locates in Center or 
Figure 2: Distribution of migrants' origin countries by GDP per capita (in terciles; source: Italian Ministry of the Interior and ISTAT).

$$
\text { (a) Italy }
$$

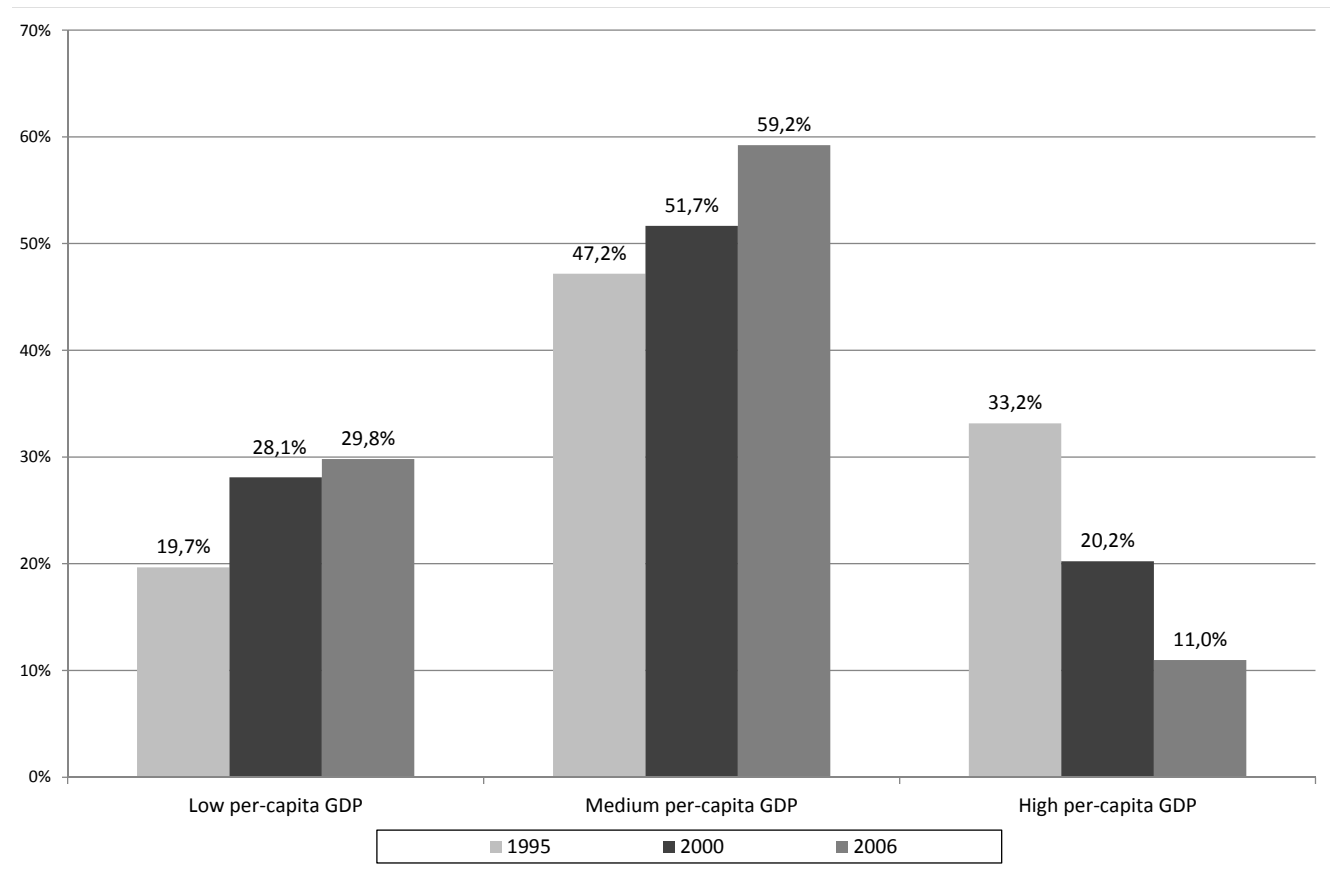

(b) Difference in the distribution according to the final location in Italy (North vs. South)

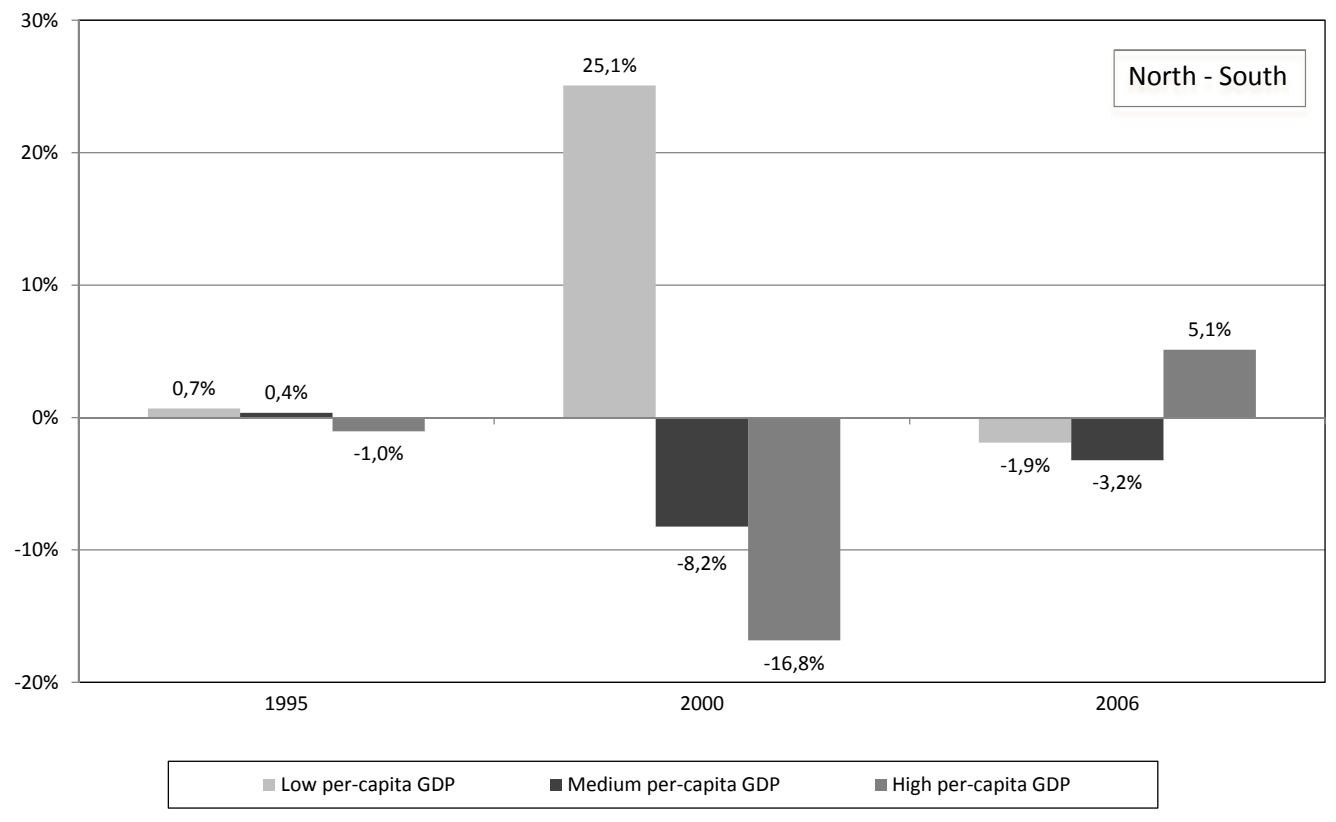


Northern Italy (see Figure 2b).

Hence, given the wide variation of countries of origin and high variability in migrants' location, we deem that the Italian case offers a double type of variability to study the effects of migrants' arrivals.

Furthermore, Figure 3 reports the sectorial distribution of migrants and natives for the years 2005 and 2006.7 Foreign-born are proportionally more represented in the industrial sector and especially in construction; although still relevant, migrants' employment share in the different types of services is lower than in the case of natives.

In the same Figure 3 we also report the relative weight of each sector in total Italian GDP. As presented below, according to our theoretical framework some sectors will not be considered in our empirical model as the disregarded sectors either present low migrants' employment or are negligible for total GDP (e.g. the Agriculture sector) ${ }^{8}$

The definition of intensiveness in terms of simple or complex tasks could be heuristic and based on common wisdom, especially when considering large sectorial aggregations as in our case.

Based on the computations shown in D'Amuri and Peri (2012) for the task content of the different occupations (see their Tables A2 and A3), we obtained the simple/non-simple content of our two major sectors (i.e. industry plus constructions and services) by weighing the task content of each occupation with the employment in each sector. Figure 4 reports our computations (see Appendix A for the sources, data and derivations). The task content is represented by the (average) percentile of employment performing that type of task less intensively in the whole economy. For instance, the score 44 for Industry in the left-handside group of histograms that refers to complex tasks means that, when comparing the tasks performed by the workers in Industry with the tasks of the workers in the whole economy, 44 percent of total employment performs complex tasks less intensively than in Industry. For Services the percentile is 58 meaning that 58 per cent of total employment performs complex

\footnotetext{
${ }^{7}$ The years 2005 and 2006 are the first two years for which these statistics are available for Italy and are the only two overlapping years with our sample. Averages of these two years are reported in the Figure 3.

${ }^{8}$ Our analysis considers large macro sectors and cannot be much finer since we want to exploit the geographical/spatial dimension. We ought to recognize this limitation makes our results .
} 


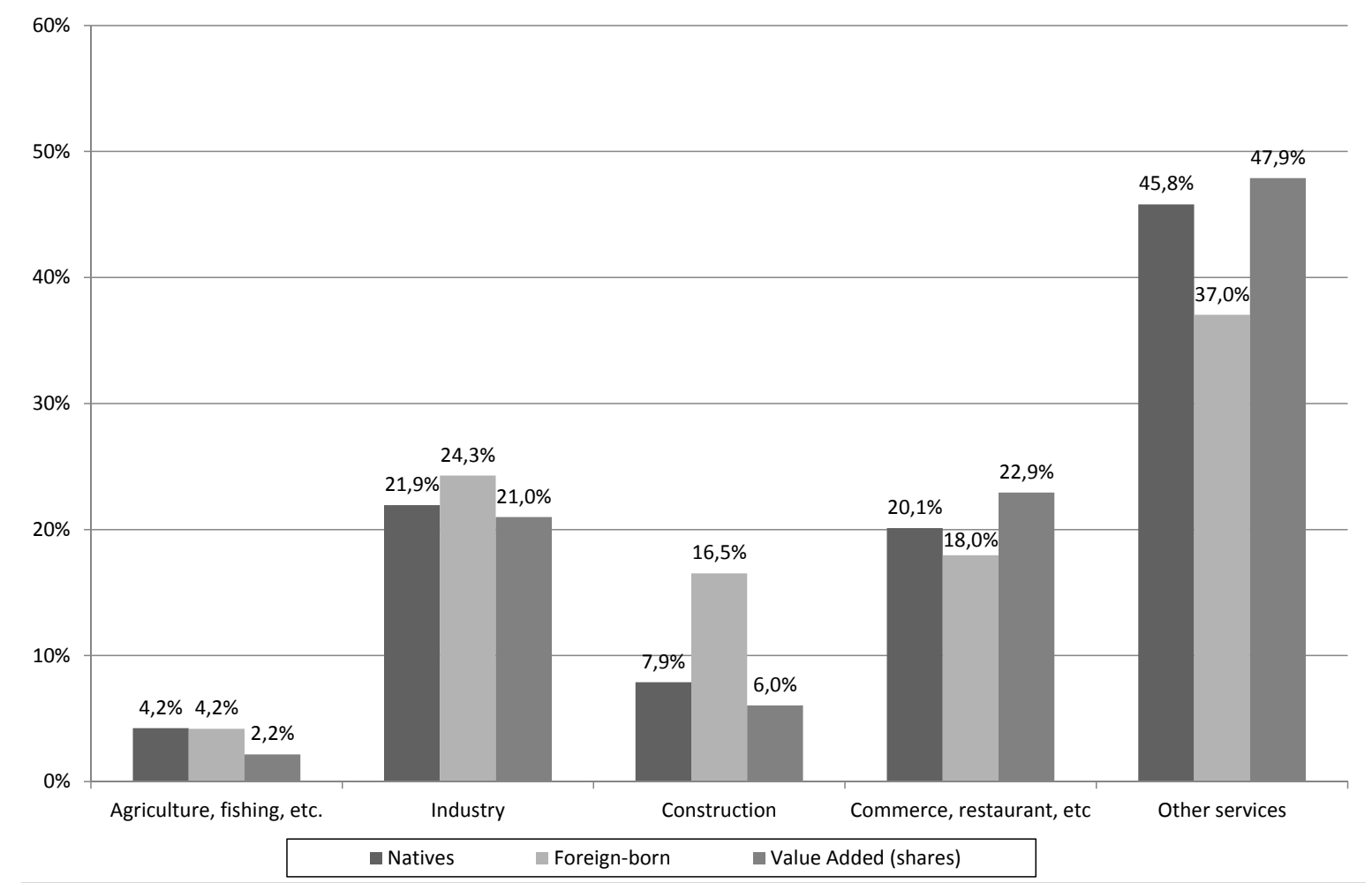

Figure 3: Employment distribution of natives and foreign-born in Italy in the main sectors; sectors' shares of value added (average 2005-06; source: Italian Institute of Statistics, ISTAT).

task less intensively. Therefore, the Services sector is characterized by workers that on average perform complex tasks more intensively than in Industry. Hence, the higher the percentile, the more intensive that sector is in that particular task.9

The ratio complex-to-simple tasks is represented to the extreme right of Figure 4. Industry/Manufacturing (including Constructions) has the lowest complex-to-simple ratio. As explained in Section 4, in our study we will use a stricter definition of complex-task intensive sector as coinciding with Services, but excluding personal and household services. This means that the complex-task intensity of our restricted Service sector would be even stronger than the one represented in Figure 4.

Finally, Figure 5 reports the geographical distribution of the two key variables of our analysis - i.e. the Manufacture-to-Service ratio and the Migrants-to-Natives ratio - when

\footnotetext{
${ }^{9}$ The computation of task intensity for each sector is obtained with the weights of each occupation in each sector. This is true also when considering the whole economy where the weights are referred to economy-wide occupation weights. Hence, as the (only) statistical-computation requirement, the histograms labeled Total show indexes between the two sector-specific ones.
} 


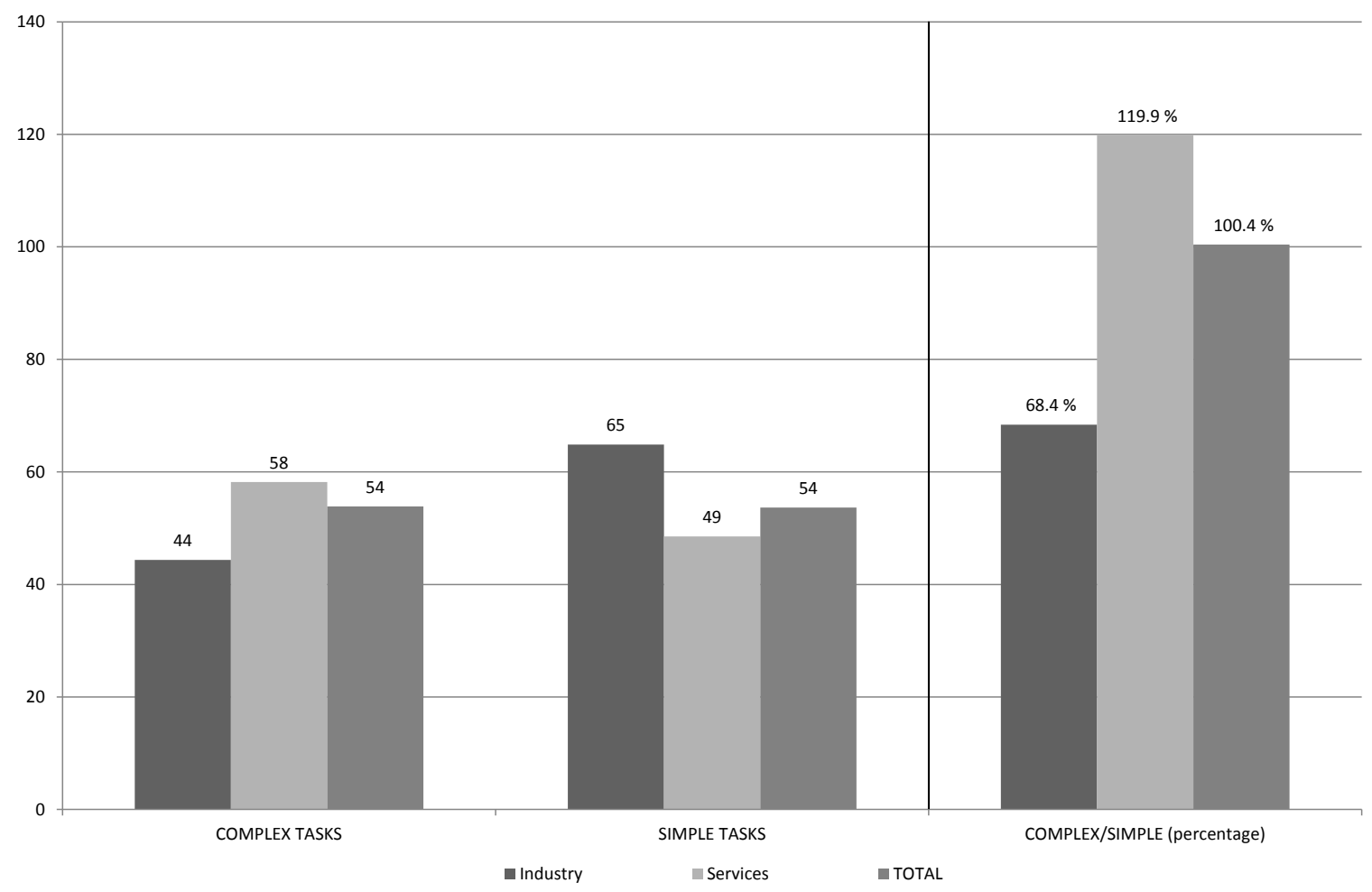

Figure 4: A Measure of Average Task Complexity by Sector in 2005 (Source: Own Computation, see Appendix A.

considering the average over our sample period (1995-2006). We can notice a clear spatial correlation between the two ratios and this will be further investigated both theoretically and empirically in the next Sections.

A further discussion on the data is reported in Section 4.

\section{Theoretical Framework}

Let us consider two sectors, manufacturing $(M)$ and services $(V)$, and assume that the two production functions are well-behaved Cobb-Douglas:

$$
Y_{j}=A_{j} H_{j}^{(1-\alpha)} N_{j}^{\alpha}
$$

Output $Y_{j}$ in each sector $j=M, V$ is produced with two different inputs: (a) the factor $H$, which is freely mobile between the two sectors, and (b) the specific factor $N_{j}$, which is characterized by a sector-specific composition of labor services. The setup is similar to 


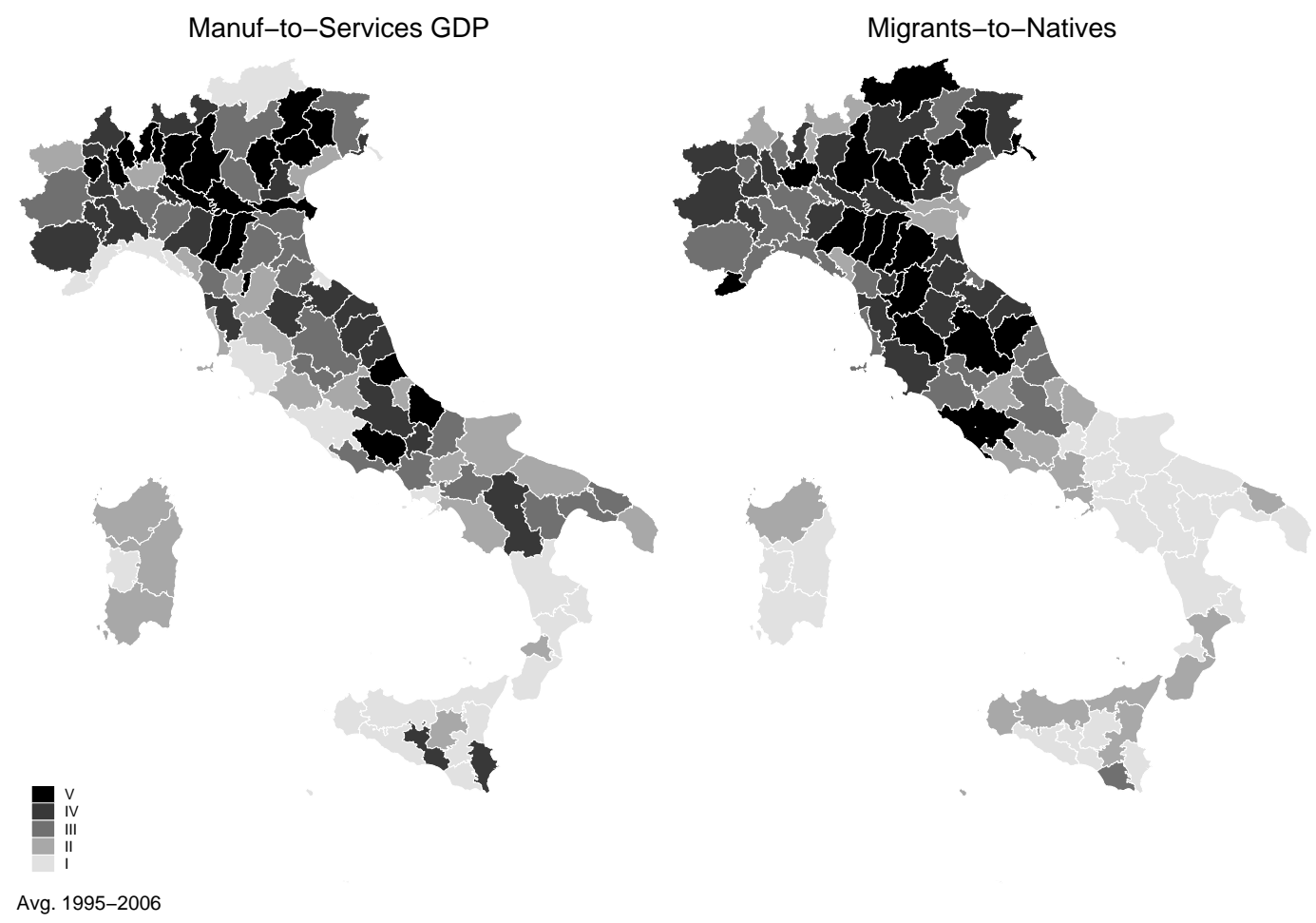

Figure 5: The Geographical Distribution of the Migrants-to-Natives Ratio and of the Manufactureto-Services Ratio (average quintiles 1995-2006: source: Italian Institute of Statistics, ISTAT).

the Ricardo-Viner specific-factor model - see Jones (1971), or Feenstra (2004) (p.72). The elasticity of output to the mobile factor $H$ is the same; the two sectors differ because of the TFP parameter $A_{j}$ and the different composition of the factor $N_{j}$.

The mobile factor $H$ can be traditionally interpreted as capital, but it can be any type of production factor that is in fixed supply in our market (being the province in our case), but that can be used by both sectors, i.e. land, a general type of labor, public services, etc ${ }^{10}$

As a consequence of the free mobility, the remuneration of $H$ has to be same in the two sectors; hence, if $A_{M}=A_{V}$ the relative production is simply a function of the relative output price and the relative specific-factors supply:

$$
\frac{Y_{M}}{Y_{V}}=\left(\frac{p_{M}}{p_{V}}\right)^{\frac{\alpha}{1-\alpha}} \frac{N_{M}}{N_{V}}
$$

\footnotetext{
${ }^{10}$ Peri and Sparber (2009) consider a CES production function in one-sector model where one of the two intermediate services corresponds to the amount of high education workers and may be similar to our specific factor.
} 
Let us assume for now that the relative price is fixed since, for instance, it is given from abroad (we assume a small-open province or region or economy) 11

Let us name $W_{H}$ the nominal "wage" of the mobile factor $H$, and $W_{j}$ for $j=M, V$ the nominal "wages" of the two specific factors. From the Cobb-Douglas characteristics:

$$
p_{j}=A^{-1} W_{H}^{1-\alpha} W_{j}^{\alpha}
$$

for $j=M, V$, where $A \equiv\left[\left(\frac{\alpha}{1-\alpha}\right)^{1-\alpha}+\left(\frac{\alpha}{1-\alpha}\right)^{-\alpha}\right]$.

Therefore:

$$
\frac{W_{M}}{W_{V}}=\left(\frac{p_{M}}{p_{V}}\right)^{\frac{1}{\alpha}}
$$

Hence, a given relative output price implies a given relative "wage" of the specific factors ${ }^{12}$

Another important consequence of (1) (and given relative prices) is that the dynamics of relative output is fully determined by the relative quantity of the two specific factors, which are composite indexes of labor services (or labor tasks).

The composite factor $N_{j}$ is a sector-specific input because of its composition in terms of labor services. We consider two different types of labor services: simple manual tasks $(S)$ and complex (abstract, communication intensive) tasks $(C)$. The labor services are combined differently in the two sectors via a CES aggregation as follows:

$$
N_{j}=\left[\beta_{j} S_{j}^{\frac{\sigma-1}{\sigma}}+\left(1-\beta_{j}\right) C_{j}^{\frac{\sigma-1}{\sigma}}\right]^{\frac{\sigma}{\sigma-1}}
$$

where the coefficient $\beta_{j}$ represents the relative productivity of simple to complex tasks and we assume that simple tasks $S$ are relatively more productive in the $M$ sector, i.e. $\beta_{M}>\beta_{V}$.

\footnotetext{
${ }^{11}$ As an alternative, we could consider a model with one nontraded sector and two traded sectors that could be aggregated into one by assuming a constant relative price ratio in the spirit of Corden and Neary (1982). The main conclusions do not change under plausible assumptions. See Appendix or available from the authors upon request.

${ }^{12}$ Data on provincial relative prices are not available. Instead, we can provide evidence on the dynamics of relative wages. In Appendix [F. Table 17 shows that relative wages are sticky over the whole period we consider.
} 
The elasticity of substitution between tasks is equal to $\sigma$ and does not change between the two sectors.

Then:

$$
\begin{aligned}
\frac{N_{M}}{N_{V}} & =\left[\frac{\beta_{M} S_{M}^{\frac{\sigma-1}{\sigma}}+\left(1-\beta_{M}\right) C_{M}^{\frac{\sigma-1}{\sigma}}}{\beta_{V} S_{V}^{\frac{\sigma-1}{\sigma}}+\left(1-\beta_{V}\right) C_{V}^{\frac{\sigma-1}{\sigma}}}\right]^{\frac{\sigma}{\sigma-1}}= \\
& =\frac{S_{M}}{S_{V}}\left[\frac{\beta_{M}+\left(1-\beta_{M}\right) c_{M}^{\frac{\sigma-1}{\sigma}}}{\beta_{V}+\left(1-\beta_{V}\right) c_{V}^{\frac{\sigma-1}{\sigma}}}\right]^{\frac{\sigma}{\sigma-1}}
\end{aligned}
$$

where $c_{j} \equiv \frac{C_{j}}{S_{j}}$ for $j=M, V$.

Equation (4) shows that the relative quantity of the two specific factors depends on the two ratios $c_{M}$ and $c_{V}$, and on the ratio $\frac{S_{M}}{S_{V}}$. Ultimately, also relative output depends on the same three ratios.

It is easy to show that when the relative price of output is given as assumed in (1), not only the relative "wage" of the two specific composite factors $\frac{W_{M}}{W_{V}}$ is given as in (2), but also the relative "wage" $\omega \equiv \frac{W_{C}}{W_{S}}$ of the two types of labor services that form the composite labor factors ( $W_{C}$ being the compensation for complex tasks and $W_{S}$ for simple tasks) - see Appendix C

\subsection{Relative demand for tasks}

Workers are assumed to freely move between the two sectors, which implies that labor services are freely-mobile between the two sectors since they travel with workers. ${ }^{13}$

It is easy to obtain the sectorial relative demand for complex tasks as a function of relative task wages, $\omega \equiv \frac{W_{C}}{W_{S}}$ :

$$
\frac{C_{j}}{S_{j}}=\left(\frac{1-\beta_{j}}{\beta_{j}}\right)^{\sigma} \omega^{-\sigma}
$$

Since $\beta_{M}>\beta_{V}$ for any given relative task wage, the service sector is always complex-task

\footnotetext{
${ }^{13}$ We ought to notice that our estimated model is based on local labor market (using data at the provincial level); so, this latter hypothesis translates into a plausible "free workers mobility within the province".
} 
intensive with respect to the manufacturing sector. $14 \frac{C_{V}}{S_{V}}>\frac{C_{M}}{S_{M}}$.

The total relative demand for complex tasks is then:

$$
\begin{aligned}
& \left(\frac{C}{S}\right)^{d}=s_{M}\left(\frac{C_{M}}{S_{M}}\right)^{d}+\left(1-s_{M}\right)\left(\frac{C_{V}}{S_{V}}\right)^{d}= \\
= & {\left[\frac{s}{s+1}\left(\frac{1-\beta_{M}}{\beta_{M}}\right)^{\sigma}+\frac{1}{s+1}\left(\frac{1-\beta_{V}}{\beta_{V}}\right)^{\sigma}\right] \omega^{-\sigma} }
\end{aligned}
$$

where $s_{M}=\frac{S_{M}}{S_{M}+S_{V}}=\frac{\frac{S_{M}}{S_{V}}}{\frac{S_{M}}{S_{V}}+1}=\frac{s}{s+1}$ is the weight of the demand for simple tasks from the $M$ sector and increases when $s=\frac{S_{M}}{S_{V}}$ increases.

\subsection{Relative supply of tasks}

By following Peri and Sparber (2009), let us consider two types of individuals $k=D, F$ respectively for native $(D)$ and for foreign-born $(F)$. Each individual is endowed with 1 unit of labor and has to decide how to optimally allocate it between simple and complex tasks.

Let $\pi_{j}$ be the relative subjective productivity of individual type $j$ in performing complex tasks to simple tasks. We assume that natives are relatively more productive in complex tasks $15 \pi_{D}>\pi_{F}$.

Wage maximization determines the optimal allocation of the labor unit and the relative $k$-individual supply of tasks is the following:

$$
\frac{c_{k}}{s_{k}}=\left(\frac{W_{C}}{W_{S}}\right)^{\frac{\delta}{1-\delta}}\left(\pi_{k}\right)^{\frac{1}{1-\delta}}
$$

where $c_{k}\left(s_{k}\right)$ is the fraction of labor unit optimally supplied for complex (simple) tasks, $k=F, D$. Not surprisingly, for the same relative wage a native individual $D$ supplies relatively more complex tasks and this is due to the fact that natives are relatively more productive in

\footnotetext{
${ }^{14}$ We have absence of task-intensity reversal.

${ }^{15}$ Peri and Sparber (2009) introduce also a parameter that may capture wage discrimination between natives and foreign-born, as shown by the literature on wage differentials. D'Amuri and Peri (2012) reformulate the optimization problem as utility maximization and assume that simple services are disliked relatively more by natives. For sake of simplicity, we omit also these dislike terms. They would only increase the number of parameters without any further insight on our proposition.
} 
complex tasks.

Still following Peri and Sparber (2009), we obtain the relative supply of tasks by weighing with the fraction of foreign-born supply of manual services:

$$
\begin{aligned}
& \frac{C}{S} \equiv \frac{C_{F}+C_{D}}{S_{F}+S_{D}} \equiv \frac{S_{F}}{S_{F}+S_{D}} \frac{C_{F}}{S_{F}}+\left(1-\frac{S_{F}}{S_{F}+S_{D}}\right) \frac{C_{D}}{S_{D}}=\phi(f) \frac{c_{F}}{s_{F}}+[1-\phi(f)] \frac{c_{D}}{s_{D}}= \\
&=\left\{\phi(f)\left(\pi_{F}\right)^{\frac{1}{1-\delta}}+[1-\phi(f)]\left(\pi_{D}\right)^{\frac{1}{1-\delta}}\right\}\left(\frac{W_{C}}{W_{S}}\right)^{\frac{\delta}{1-\delta}}
\end{aligned}
$$

where $f=\frac{L_{F}}{L_{F}+L_{D}}$ is the fraction of foreign-born residents; $0<\phi(\cdot)<1$ is monotonically increasing, $\phi(0)=0$ and $\phi(1)=1$.

When $f$ increases there is a recomposition effect in favor of simple labor services and for any given relative wage there is a decrease in the relative supply of complex-to-simple tasks; formally $\frac{\partial \frac{C}{S}}{\partial f}<0$.

\subsection{Equilibrium and Discussion}

Equilibrium in the markets for tasks is obtained in relative terms by considering the demand and supply of complex-to-simple labor services and the relative wage of complex-to-simple labor services.

As shown in Section 3.1, when the output price ratio is given at $p^{*}$, the relative wage of the specific factors is given, as well as the relative wage of labor services $\omega \equiv \frac{W_{C}}{W_{S}}=\omega^{*}$. Therefore, the relative supply $\frac{C}{S}$ from Equation 8 is determined:

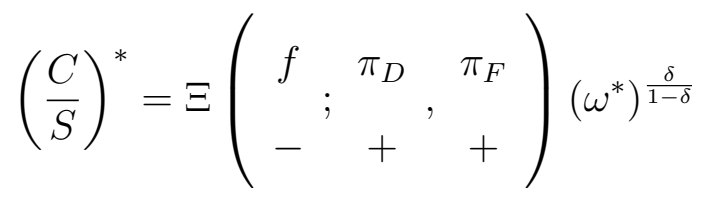

In equilibrium total relative supply is equal to total relative demand, as given from Equation (6): 


$$
\Xi\left(f ; \pi_{D}, \pi_{F}\right)\left(\omega^{*}\right)^{\frac{\delta}{1-\delta}}=\left[\frac{s}{s+1}\left(\frac{1-\beta_{M}}{\beta_{M}}\right)^{\sigma}+\frac{1}{s+1}\left(\frac{1-\beta_{V}}{\beta_{V}}\right)^{\sigma}\right]\left(\omega^{*}\right)^{-\sigma}
$$

where the unknown is the relative weight $s$, i.e. the relative weight of the $M$ sector:

$$
s \equiv \frac{S_{M}}{S_{V}}=\frac{c_{V}\left(\omega^{*}\right)-c\left(\omega^{*} ; f ; \pi_{D}, \pi_{F}\right)}{c\left(\omega^{*} ; f ; \pi_{D}, \pi_{F}\right)-c_{M}\left(\omega^{*}\right)}
$$

where

$$
\begin{gathered}
c\left(\omega^{*} ; f ; \pi_{D}, \pi_{F}\right) \equiv \Xi\left(f ; \pi_{D}, \pi_{F}\right)\left(\omega^{*}\right)^{\frac{\delta}{1-\delta}} \\
c_{j}\left(\omega^{*}\right) \equiv\left(\frac{1-\beta_{j}}{\beta_{j}}\right)^{\sigma}\left(\omega^{*}\right)^{-\sigma} \quad \text { for } j=M, V
\end{gathered}
$$

The derivation of the equilibrium highlights the main difference between this paper's twosector approach and the previous one-sector model, as in Peri and Sparber (2009).

In the one-sector model the equilibrium variable is the relative wage. In the present twosector model for a small open region where relative prices and wages are predetermined by exogenous conditions, the relative supply of tasks is given, as well as the relative demand for tasks in each of the two sectors. Hence, the equilibrium variable must be the relative weight of the two sectors (i.e. the ratio $s$ above) so that the weighted sum of demand from the two sectors matches the given relative supply of tasks.

\subsection{Increase in Foreign-Born Residents}

Let us consider an increase in the fraction $f$ of foreign-born residents.

Equation (9) shows that when $f$ rises the relative supply of overall complex tasks lowers.

Since the relative wage does not change, then the relative demand must decrease of the same amount.

The two sectorial relative demand for complex-to-simple labor services depends only on the relative wage of tasks that does not change. Hence, the only reduction in total relative 


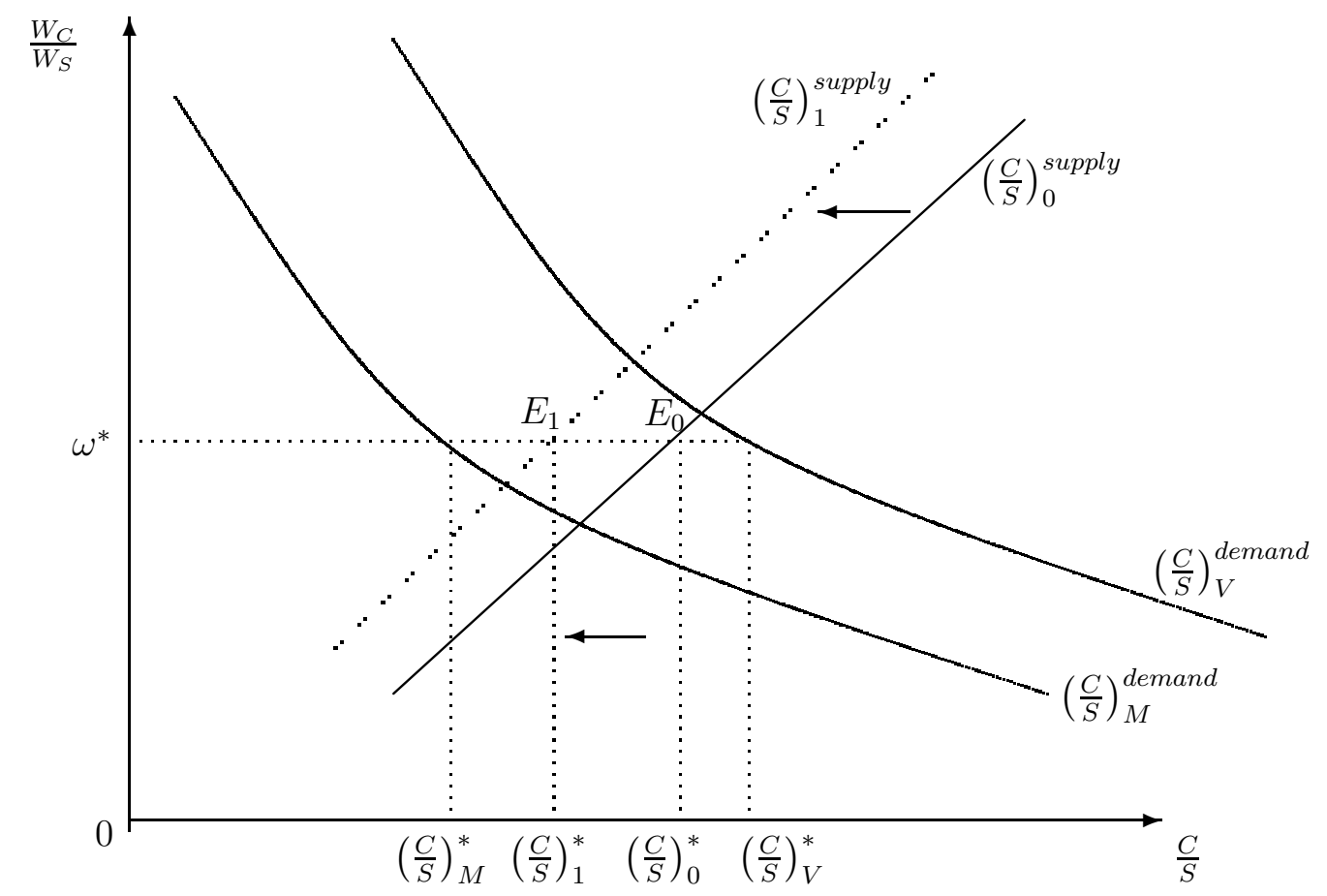

Figure 6: Effect of the increase in $f$ in the complex-to-simple-tasks ratios.

demand can occur via a recomposition of the total demand that occurs by an increase in the weight to the less complex-task intensive sector, i.e. the $M$ sector.

Formally, it is easy to see in Equation 10 that when $c\left(\omega^{*} ; f, \cdot\right)$ lowers because there is an increase in $f$ and $\omega^{*}$ does not change - hence, letting $c_{V}$ and $c_{M}$ be constant - then the $s$ ratio increases. Consequently, the sector-specific composite factors and the output ratio change in favor of the simple-task-intensive sector, i.e. both $\frac{N_{M}}{N_{V}}$ and $\frac{Y_{M}}{Y_{V}}$ rise when $f$ increases.

Graphically, the increase in $f$ is represented in Figure 6 by an upward shift in the relative supply of tasks. The equilibrium moves from $E_{0}$ to $E_{1}$ with a contraction in the overall complex-to-simple-tasks ratio from $\left(\frac{C}{S}\right)_{0}^{*}$ to $\left(\frac{C}{S}\right)_{1}^{*}$. Since the wage ratio remains constant, the relative demand for tasks in the two sectors are also constant and equals to $\left(\frac{C}{S}\right)_{M}^{*}$ and $\left(\frac{C}{S}\right)_{V}^{*}$. The decrease in the overall relative demand for tasks is then possible only by means of a larger weight for the $M$ sector, i.e. the sector with the lower requirement of complex-to-simple-task ratio at the current relative wage 16

\footnotetext{
${ }^{16}$ Appendix $\mathrm{B}$ discusses the welfare implications of the migrants' inflow.
} 


\subsection{Heterogeneous Immigration}

Let us assume that foreign-born residents are not homogeneous, but they differ in terms of relative productivity in complex tasks. For simplicity, let us assume that there are two types of foreign-born residents (1 and 2) and that: $\pi_{D}>\pi_{F}^{1}>\pi_{F}^{2}$. From Equation (7) it is easy to rank their individual relative task supply: $\frac{c_{k}^{1}}{s_{k}^{1}}>\frac{c_{k}^{2}}{s_{k}^{2}}$

Then the average relative supply of the overall foreign-born is the following:

$$
\frac{C_{F}}{S_{F}} \equiv \frac{S_{F}^{2}}{S_{F}^{2}+S_{F}^{2}} \frac{C_{F}^{2}}{S_{F}^{2}}+\left(1-\frac{S_{F}^{2}}{S_{F}^{2}+S_{F}^{2}}\right) \frac{C_{F}^{1}}{S_{F}^{1}}=\lambda(g) \frac{c_{F}^{2}}{s_{F}^{2}}+[1-\lambda(g)] \frac{c_{F}^{1}}{s_{F}^{1}}
$$

where $g=\frac{L_{F}^{2}}{L_{F}^{1}+L_{F}^{2}}$ and $L_{F}^{i}$ is equal to the number of foreign-born residents of type $i=1,2$ and the $\lambda(\cdot)$ function has the characteristics of the $\phi(\cdot)$ function: $\lambda(0)=0, \lambda(1)=1,0<\lambda(\cdot)<1$ and is monotonically increasing.

The overall supply is therefore:

$$
\begin{gathered}
\frac{C}{S} \equiv \frac{S_{F}}{S_{F}+S_{D}} \frac{C_{F}}{S_{F}}+\left(1-\frac{S_{F}}{S_{F}+S_{D}}\right) \frac{C_{D}}{S_{D}}=\phi(f) \frac{c_{F}}{s_{F}}+[1-\phi(f)] \frac{c_{D}}{s_{D}}= \\
=\phi(f) \lambda(g) \frac{c_{F}^{2}}{s_{F}^{2}}+\phi(f)[1-\lambda(g)] \frac{c_{F}^{1}}{s_{F}^{1}}+[1-\phi(f)] \frac{c_{D}}{s_{D}}
\end{gathered}
$$

An increase in $g$, i.e. in the fraction of less productive migrants in complex tasks, for a given $f$, lowers the relative supply of complex tasks more since the composition effect gives more weight to the migrants who are relatively less productive in complex tasks.

\section{Data and Descriptive Statistics}

The main objective of this paper is to analyse the relation between migration ${ }^{17}$ and the production structure of the Italian economy over the period of more intense and significant increase in foreign-born presence, 1995-2006, in order to reconcile this picture with the theory

\footnotetext{
${ }^{17}$ We refer here to migration as measured by stock of foreign-born individuals. No data on pure flows are available in Italy at the disaggregated level; hence, when we address "flows" we are actually using stock variations.
} 
exposed in the previous section, in particular we would like to verify the presence of what resembles a Rybczynski effect.

The analysis is conducted at the level of Province, i.e. NUTS3 18

We deem Province as the finest geographical entity to investigate the migration effects and this choice is justified by two main reasons. First, detailed data on residence permits, including origin countries, are not available at a finer level than the Province. Second, the fact of being well-confined areas allows us to avoid the size effect of the Modifiable Area Unit Problem (see Briant et al. 2010 on the issue) ${ }^{19}$

Regarding migration, we use data on residence permits (see the Figure 1 above) in 19952006 20 Detailed measures of residence permits can go back to 1992, but we use 1995 as the starting date since previous years were not reliable and less representative of the migration phenomenon due to low numbers, especially when considering data at the provincial level. Due to the EU Eastern enlargement in 2004-2007, the requirement for residence and work permits has been levied for some relevant nationalities (like migrants from Romania and Poland) and they are aggregated to all the other EU non-Italian citizens as of 2007-2008. So, we considered 2006 as the ending year of our study.

In Section 2 we have already underlined the two main characteristics of the Italian immigration: rapidity and cultural diversity.

Data on the local production structures are publicly available on a yearly base from the ISTAT. In details, production data are aggregated value added for six macro-sectors: agriculture, construction, manufactures, retail and professional services (i.e. logistics, ICT etc.), financial services, household services. While our series of manufactures coincides with the aggregate

\footnotetext{
${ }^{18}$ The number of Province increases over the sample period due to the creation of new provinces. We use data that consistently refer to the initial 1995 distribution with 103 entities. We recall that the 103 Italian provinces have an average size of $\mathrm{km}^{2} 2,800$ with a coefficient of variation at 0.17 . They are 57 times tinier than American states and more than 200 times smaller than the Canadian provinces. They are also smaller and more regular in size with respect to French metropolitan departements and Spanish provinces.

${ }^{19}$ This same geographical entity is used in Bratti et al. (2014) for an analysis of the pro-trade effect of migration and in Jayet et al. (2010) to study the network effect on Italian migration.

${ }^{20}$ They slightly differ from the data on population registers since minors are not counted separately and are included in the residence permits of their custodians. Data on residence permits are released by ISTAT (Italian National Institute of Statistics), but they refer to data from the Ministry of the Interior through their local offices (Questure).
} 
originally reported by ISTAT to which we add constructions ${ }^{21}$ our definition of services includes retail and professional services, financial services, but excludes household services in order to consider a subset that could plausibly be considered as complex-task intensive.

Our dataset for production covers the period from 1995 to 2006. In Table 1 we report some general characteristics of the provinces, including some general infrastructure indexes that may be important to control for the local economic environment.

Table 1: Summary Statistics

\begin{tabular}{cccccccc}
\hline variable & mean & $\mathrm{sd}$ & $\min$ & $\mathrm{p} 25$ & $\mathrm{p} 50$ & $\mathrm{p} 75$ & $\max$ \\
\hline$V A_{\text {man }} / V A_{\text {serv }}$ & 0.49 & 0.23 & 0.10 & 0.29 & 0.48 & 0.63 & 1.24 \\
Migrants (per 1000 inhab.) & 23.79 & 17.63 & 0.30 & 10.17 & 18.43 & 34.06 & 98.10 \\
Migr/Pop & 0.02 & 0.02 & 0.00 & 0.01 & 0.02 & 0.03 & 0.10 \\
Density (per sq-km) & 243.47 & 329.01 & 22.99 & 103.68 & 172.08 & 258.14 & 2639.63 \\
Graduate (per 1000 inhab.) & 2.35 & 3.37 & 0.00 & 0.00 & 0.70 & 3.79 & 22.01 \\
Airports (runaway km) & 29.28 & 76.33 & 0.00 & 0.00 & 0.00 & 29.94 & 637.33 \\
Highways (km) & 24.99 & 20.82 & 0.00 & 10.06 & 23.00 & 34.37 & 94.09 \\
\hline
\end{tabular}

Note: $V A_{\text {man }} / V A_{\text {serv }}$ represents the manufactures value added over service sector, Migrants reports the number of foreign born residents over the overall population (1000 inhabitants) and Migr/Pop is the Migrants-to-Population ratio; Density is the number of residents by squared km, Graduates is the number of college graduates over the population; Airports and Highways are measured as the runaway/road extension per squared $\mathrm{km}$. All the variables are referred to the province level.

\section{Econometric Strategy}

In order to provide empirical evidence for our theoretical findings we estimate the relationship between the extent of migrants in province $i$ at time $t$ - measured by the ratio of the foreign presence to the native population - and the relative value added of manufacturing with respect to services.

Many other studies have used regional data within the same country in order to evaluate the effect of migration on wages ${ }^{22}$ Concerns about the use of regional data have been raised

\footnotetext{
${ }^{21}$ From Figure 3 we notice that the construction sector is important because the employment share of foreign-born is particularly relevant, although the total weight in GDP is lower than 10 percent. Estimation results not including the construction sector are similar to the ones presented below and are available from the authors upon request.

${ }^{22}$ See, for instance, Glitz (2012) for Germany and González and Ortega (2011) for Spain.
} 
following the remark by Borjas et al. (1996) that regional variability of wages within the same country could be too low since there may be a lot of co-variation due to nation-wide effects.

This concern is less important in our case since the production structure varies among the regions of the same country. Moreover, a possible (but very unlikely) nation-wide effect may work against our possible findings.

According to our model, an inflow of migrants generates an overall positive effect on the relative value added of manufacturing. A variation in the migrants-to-natives population ratio is assumed as a reliable indicator for the changes in the composition of relative task supply. This effect should be more intense when the new migrants are more diverse from natives in terms of relative productivity. Therefore, we want to investigate not only the overall effect of migrants' inflows, but also the separate effect of different types of migrants arriving in the Italian provinces - i.e. a change in the relative task supply referred not only to Equation (8), but also to Equation (11).

We use the logarithm of migrants-to-native population ratio in province $i$ at time $t, \ln$ Migr/Pop $i t$, as our covariate of interest and specify the general econometric model as follows:

$$
\begin{aligned}
& \ln \left(V A_{\text {man }} / V A_{\text {serv }}\right)_{i t}=\beta_{0}+\beta_{1} \ln \text { Migr } / \text { Pop }_{i t}+ \\
& + \text { other covariates }+ \text { fixed and time effects }+\epsilon_{i t}
\end{aligned}
$$

where our dependent variable of interest $\ln \left(V A_{\text {man }} / V A_{\text {serv }}\right)_{i t}$ is the $\log$ of the ratio of the value added in manufacturing to the value added in service sectors in province $i$ and time $t$.

Among the fixed effects and some of the covariates we must include variables that would take into account the natural and/or historical advantages of some provinces and that may affect the relative value added as time-invariant unobserved heterogeneity (Combes et al. 2011).

The time effect represents time-specific factors that can influence the provincial valueadded distribution, i.e. macroeconomic cycles, national political elections, national labor 
market reforms etc.

Equation 12 can be estimated by simple OLS under different specifications with alternative sets of covariates, as reported in the following section. However, in order to consistently estimate $\beta_{1}$, we need to address several econometric issues and provide an appropriate econometric strategy.

Indeed, as usually reported in the economic literature on migration, the covariate representing migrants' presence and location may not be orthogonal to innovations in the relative value added causing simultaneous equation bias. Many reasons have been proposed. Among those, migrants' location choices are not random; the drivers for these choices - e.g. network effects, economic magnet effects, etc. - vary over time, therefore we need some kind of instrument to exploit the variation from these effects to relative value added.

The literature on migration offers many suggestions on exclusion restrictions for our case. The simplest one is the use of imputed migrants, as in Altonji and Card (1991), where the province-nationality distribution coincides and does not change from the first available period, which is 1991 for us. This strategy relies on the fact that the presence of immigrants from a given country in a given province is likely to decrease costs and increase returns of immigration for new immigrants: co-nationals may offer hospitality, financial support and share information on the local labor market. Our instrument would be obtained by allocating the stock of immigrants in Italy (for each year) to each province using the distribution of immigrants by nationality across provinces in 1991. It is worth to notice that Card-type instruments are very suitable in order to exploit cross-sectional variations, but less useful if we have to deal with a panel dataset that shows high persistence and a feeble cross-sectional variability, because of that we tried to implement a more reliable strategy for our case.

As in Ortega and Peri (2014) we build our instrument relying on a gravity-model approach, i.e. by including only those determinants of bilateral migration flows that are exogenous to specific location decision, along with the lagged stock of migrants (to account for social network effects). Namely, we use this type of instrument in order to isolate all the factors that affect solely migration costs (see Ortega and Peri 2014). More precisely, we estimate a gravity 
equation of migration flows from country $j$ to province $i$ relative to natives population in province $i$ at time $t$ based on the following specification:

$$
\begin{aligned}
\ln \text { Migr } / P_{\text {op }}{ }_{i j t} & =\alpha_{0}+\delta_{1} \ln (P O P)_{j t}+\delta_{2} \ln (A R E A)_{j}+\delta_{3} \ln (P O P)_{i t}+\delta_{4} \ln (A R E A)_{i} \\
& +\delta_{5} \ln (D I S T)_{i j}+\delta_{6} \text { BORDER }_{i j}+\delta_{7} L A N G U A G E_{j} \\
& +\delta_{8} C O L O N Y_{j}+\delta_{9} L A N D L O C K E D_{j}+\delta_{10} S T O C K_{i j}^{1991}+\epsilon_{i j t}
\end{aligned}
$$

where: $\ln$ Migr $/$ Pop $_{i j t}$ is the share of migrants over natives; $\ln (P O P)_{j t}$ and $\ln (A R E A)_{j}$ are the log of population and area of country $j$ while $\ln (P O P)_{i t}$ and $\ln (A R E A)_{i}$ refer to province $i ; \ln (D I S T)_{i j}$ is the log of distance between country $j$ and province $i$; BORDE $R_{i j}$ is a dummy equal to one if country $j$ and province $i$ share a common border; $L A N G U A G E_{j}$ is a dummy equal to one if in country $j$ at least $9 \%$ of the population speaks Italian; $C O L O N Y_{j}$ is equal to one if the country was a former Italian colony ${ }^{23} L A N D L O C K E D_{j}$ is a dummy equal to one if the origin country is landlocked; finally $S T O C K_{i j}^{1991}$ controls for the stock of migrants in year 1991 (i.e. Network Effect) ${ }^{24}$

To ensure that we only exploit exogenous variability we estimate the baseline gravity equation without including any time varying fixed effects. As a robustness check we also estimate more structural versions of Equation (13). We progressively include time-varying fixed effects to account for Multilateral Resistance Terms (Anderson and van Wincoop, 2003) Moreover we also use Pseudo Maximum Likelihood PPML (Santos Silva and Tenreyro, 2006) estimator. Since our results are fully robust (see Table 11 in Appendix E) we prefer a plain estimation strategy. Hence, our main instrument for the migrants-to-natives ratio is given by the OLS predicted bilateral migrant share from Equation $\sqrt{13}):$ Migr/Pop$p_{i j t}=\exp \left(\Pi_{i j t} \widehat{\delta}\right)$; where $\Pi_{i j t}$ contains the whole set of regressors and $\widehat{\delta}$ contains the estimated coefficients in Equation (13). Figure 7a shows the correlation between the gravity instrument and the actual

\footnotetext{
${ }^{23}$ Note that Italy share a common language only with Switzerland, while Eritrea, Libya and Somalia are the only former colonies of the country. Results are robust to the exclusion of those variables.)

${ }^{24}$ See Mayer and Zignago (2011) for the data sources of the estimation of Equation (13).

${ }^{25}$ When this is the case we do not use the estimated fixed effects to build our instrument
} 
migrants-to-natives ratio and ensure relevance for our instrument.

There is another possible source of variation that can be exploited in order to strengthen validity of our instrumental variable. As we mentioned in the previous Section 2 (see Figure 1), over the period 1995-2006 there were three major amnesties which had a considerable impact on the migrant empirical distribution, causing an exogenous positive shocks in the amount of legal migrants present in the national territory. These policy shocks seems to be a good candidate for an additional instrument.

We build our policy instrument as follows: we interact a dummy variable that takes a value of one for the year following national amnesty with the difference between $\widehat{\text { Migr/Pop }} p_{i j t}$ and Migr/Pop ${ }_{i j t}$ (i.e. among predicted and observed migrants-to-natives ratio). The difference between predicted and observed values represents the exogenous shock in the migrant stock induced by the amnesty. An additional advantage is that we end up with an overidentified equation that allows us to test for the validity of our set of instruments under the assumption that at least one is exogenous. The rationale for the validity of our policy instrument relies on the fact that amnesties were not planned and not related either on demand factors or on specific needs of the local industries. As a consequence, the relative provincial value added cannot be a predictor of the shocks generated by the amnesties. The difference in observed versus predicted migrant level (our instrument) can be therefore interpreted as a pure supply shock on the migrants-to-native ratio. Figure $7 \mathrm{~b}$ confirms the relevance of our policy instrument. The use and the derivation of this latter instrument lead us to a straightforward interpretation of the coefficient $\beta_{1}$ in the second stage as a local average treatment effect (LATE).

Although evidence on our instruments is quite comforting, we cannot disregard their limitations. As underlined in Ortega and Peri (2014) the use of the gravity equation for trade or migration flows requires some modeling choices - specifically, the resulting structural equations prescribe a full set of origin and destination fixed effects to avoid omitted variable bias in the estimated coefficients.

In our baseline estimation, following Ortega and Peri (2014), we decided to exclude all fixed effects in building our gravity instrument. When doing that we are exploiting only 
Figure 7: Relationship between the Migrants-to-Natives Ratio and its Instruments.

(a) Correlation with the Gravity Instrument

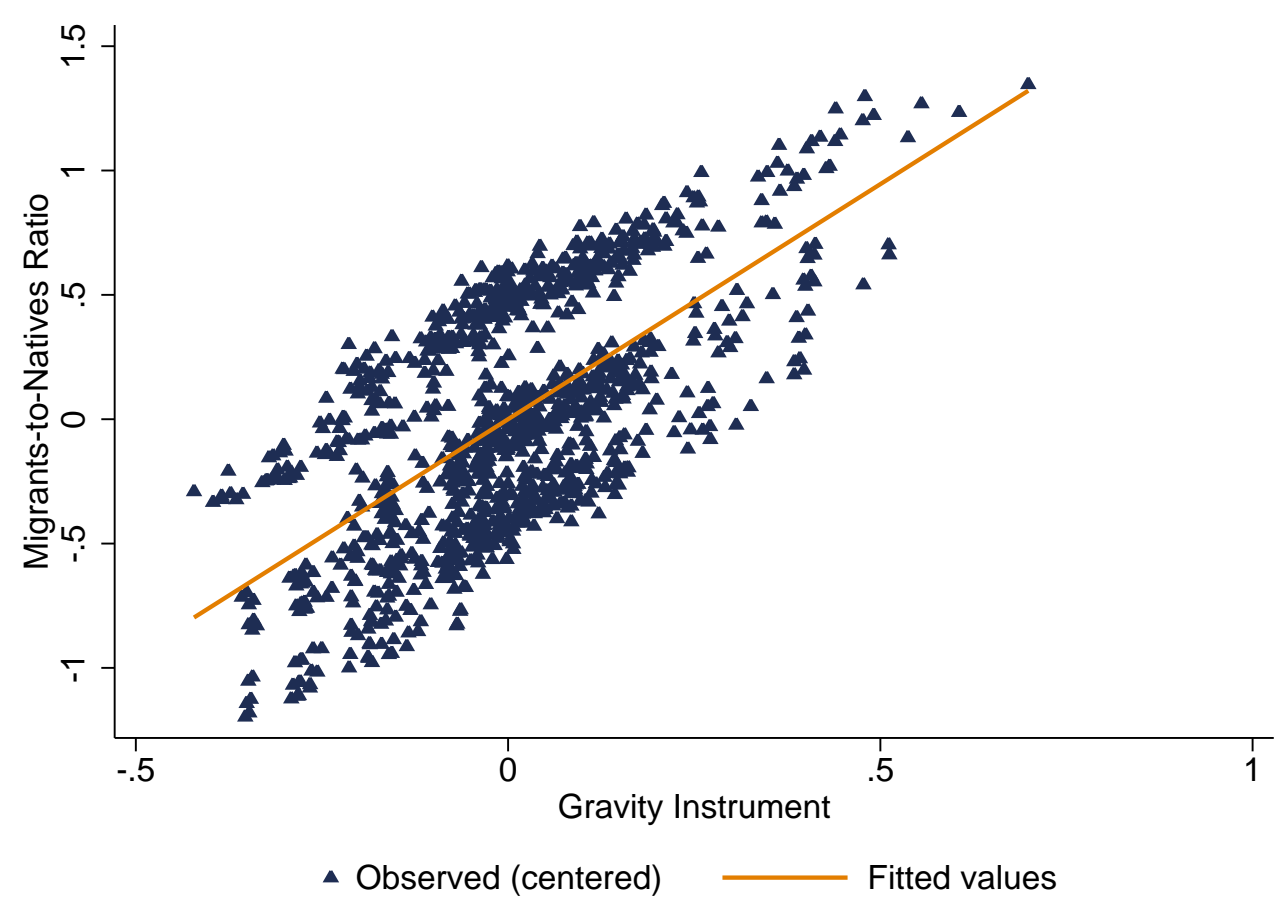

(b) Correlation with the Policy Instrument

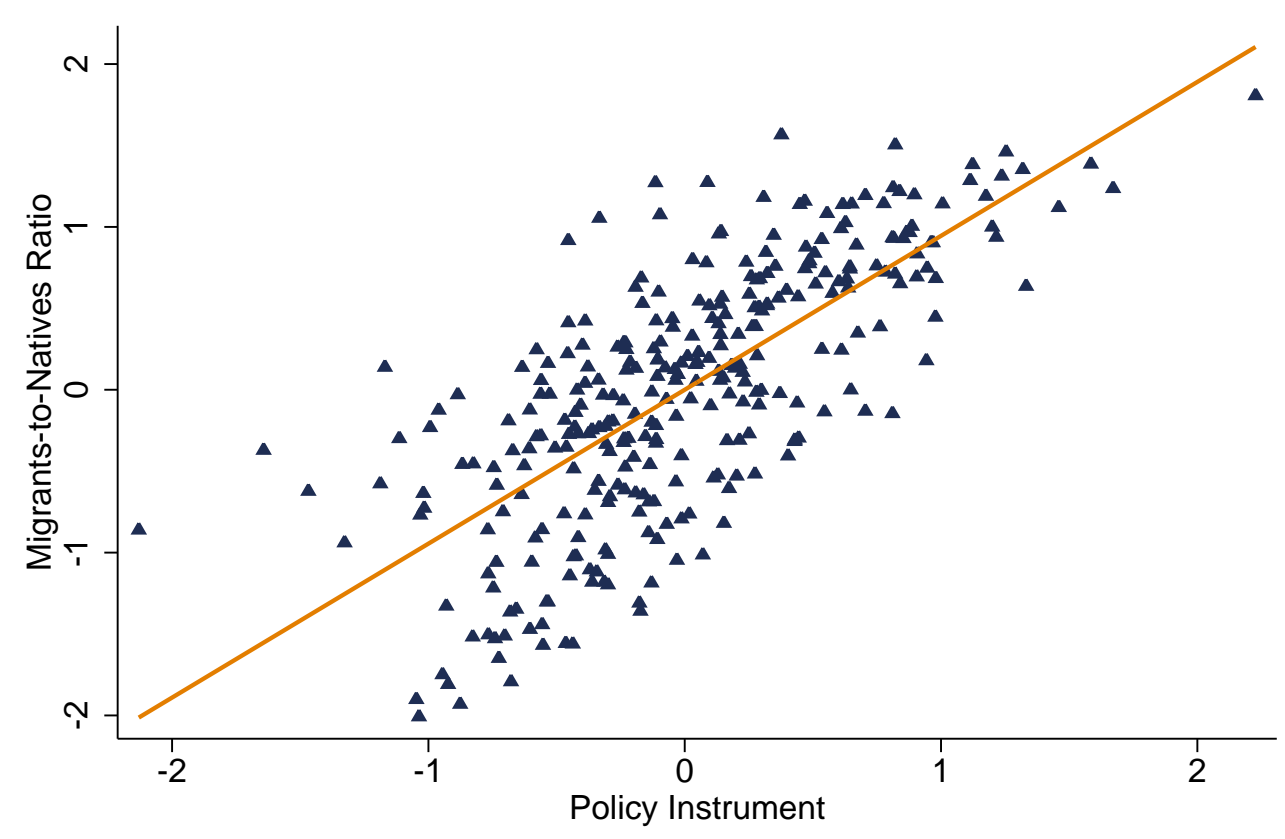

- $\ln (\mathrm{Mig} / \mathrm{Pop})$ Fitted values 
the exogenous determinants of migration flows to build our instrument. Indeed, including destination-country fixed effects would capture also the change in local production structure, which is likely to be a major source of endogeneity for our second stage estimation ${ }^{26}$

As shown below in Section 6, we perform a full set of robustness check including progressively all the prescribed fixed effects to estimate a proper structural gravity equation. We build our instrument using only the coefficients (properly estimated) for the exogenous determinants of migration, leaving aside the estimated fixed effects. The results reported in Table 3 in the next section confirm that our findings are not driven by the gravity specification.

Second, regarding the policy instrument, we should recognize the importance of illegal migration and the fact that, although migrants may not appear in the statistics, they were already employed and affected the value added of all sectors. Indeed, the statistics on value added (adjusted for irregular employment by the Italian Institute of Statistics, ISTAT) include indirectly the effect of working undocumented migrants. However, the amnesties and the legalization of the labor contracts must have had an effect on value added via the increase in the regular labor supply (for instance, regularized migrants may have taken different tasks from irregular ones). This assumption is essential in order to maintain the validity of our instrument 27

\section{$6 \quad$ Estimation Results}

In Table 2 we show a series of results for our baseline regression, Equation (12). A first set of models are estimated by OLS. The first column reports the most parsimonious specification without covariates or fixed effect, whereas we include time dummies in column (2) then only province covariates column (3), and finally province controls plus time dummies, column (4). In line with our theoretical findings, we confirm a positive sign for $\beta_{1}$ for all four specifications.

The last two columns in Table 2 show OLS estimates when we include fixed effects via the

\footnotetext{
${ }^{26}$ As kindly suggested by one of the referees, even if causality were driven by a reverse effect (i.e., changes in production structure attracts further immigrants), our results still attest native/immigrant differences.

${ }^{27}$ This latter assumption is also important so that the expected change of the regularization of irregular migrants on value added saves our interpretation of $\beta_{1}$ as a local average treatment effect.
} 
Table 2: Baseline Estimation

\begin{tabular}{|c|c|c|c|c|c|c|}
\hline $\begin{array}{l}\text { Dep. Var: } \\
\ln \left(V A_{\text {man }} / V A_{\text {serv }}\right)\end{array}$ & (1) & (2) & $(3)$ & (4) & $\begin{array}{l}(5) \\
\mathrm{FE}\end{array}$ & $\begin{array}{l}(6) \\
\text { FD } \\
\end{array}$ \\
\hline $\ln M i g r / P o p$ & $\begin{array}{c}0.079^{* * *} \\
(0.019)\end{array}$ & $\begin{array}{c}0.134^{* * *} \\
(0.022)\end{array}$ & $\begin{array}{c}0.119^{* * *} \\
(0.018)\end{array}$ & $\begin{array}{c}0.185^{* * *} \\
(0.021)\end{array}$ & $\begin{array}{c}0.004 \\
(0.019)\end{array}$ & $\begin{array}{r}0.022^{* *} \\
(0.011)\end{array}$ \\
\hline Density & & & $\begin{array}{l}0.036^{*} \\
(0.020)\end{array}$ & $\begin{array}{c}0.027 \\
(0.019)\end{array}$ & $\begin{array}{c}0.074 \\
(0.103)\end{array}$ & $\begin{array}{l}0.204^{*} \\
(0.103)\end{array}$ \\
\hline Graduate & & & $\begin{array}{c}-10.445^{* *} \\
(4.624)\end{array}$ & $\begin{array}{l}-5.916 \\
(4.391)\end{array}$ & $\begin{array}{l}-0.966 \\
(2.824)\end{array}$ & $\begin{array}{l}-0.740 \\
(3.051)\end{array}$ \\
\hline Highways & & & $\begin{array}{c}-0.028^{* *} \\
(0.013)\end{array}$ & $\begin{array}{c}-0.041^{* * *} \\
(0.012)\end{array}$ & $\begin{array}{l}-0.186 \\
(0.154)\end{array}$ & $\begin{array}{l}-0.137 \\
(0.136)\end{array}$ \\
\hline Airports & & & $\begin{array}{c}-0.073^{* * *} \\
(0.008)\end{array}$ & $\begin{array}{c}-0.076^{* * *} \\
(0.008)\end{array}$ & $\begin{array}{l}-0.003 \\
(0.014)\end{array}$ & $\begin{array}{c}-0.022^{* *} \\
(0.009)\end{array}$ \\
\hline Observations & 1,133 & 1,133 & 1,133 & 1,133 & 1,133 & 1,1030 \\
\hline R-squared & 0.029 & 0.082 & 0.193 & 0.258 & 0.963 & 0.060 \\
\hline Fixed Effects & No & $\mathrm{t}$ & No & $\mathrm{t}$ & $\mathrm{i}, \mathrm{t}$ & $\mathrm{i}, \mathrm{t}$ \\
\hline
\end{tabular}

Standard errors (in parenthesis) are robust to heteroscedasticity and arbitrary autocorrelation ${ }^{* * *} \mathrm{p}<0.01$, ** $\mathrm{p}<0.05,{ }^{*} \mathrm{p}<0.1$.

within transformation - column (5) - and via the first-difference transformation - column (6). In both cases we obtain positive estimates for $\beta_{1}$, but interestingly the coefficient of column (6) is greater and slightly more precisely estimated than the one in column (5). Both of them should be interpreted as biased estimates of the true coefficient since both are affected by the presence of unobserved time-varying characteristics that cannot be ruled out through these transformations. As noted in Bartolucci et al. (2005) if the unobserved time varying characteristics is time-dependent, first-difference estimators are more robust since its inconsistency does not depend on time ${ }^{28}$ In light of these results, the two biased results in column (5) and (6) can give a hint for the direction of the bias. Therefore, we should expect that the true coefficient would be positive and greater than 0.022 and an appropriate IV method should provide such an outcome.

In Table 3 we use the IV-2SLS approach and we also control for unobserved heterogeneity at the Province level. When we include fixed effects to control for natural (time invariant) unobserved characteristic, $\beta_{1}$ saves its sign and significance.Moreover, the point value of the

\footnotetext{
${ }^{28}$ Intuitively this suggests that the first difference coefficient remains relatively near to the true value when time increases if compared with the coefficient estimated through within transformation, which in turn will be more intensively biased. A similar result is noted by Wooldridge (2010) for the case in which covariates are weakly dependent and error stationary
} 
Table 3: 2SLS Estimation, Province Fixed Effects

\begin{tabular}{lcccc}
\hline & $(1)$ & $(2)$ & $(3)$ & $(4)$ \\
Dep. Var: & \multicolumn{4}{c}{$\ln \left(V A_{\text {man }} / V A_{\text {serv }}\right)$} \\
\hline ln Migr/Pop & $0.157^{* * *}$ & $0.128^{* *}$ & $0.186^{* *}$ & $0.172^{* * *}$ \\
& $(0.056)$ & $(0.055)$ & $(0.073)$ & $(0.065)$ \\
Density & -0.097 & -0.064 & -0.129 & -0.113 \\
& $(0.128)$ & $(0.123)$ & $(0.144)$ & $(0.136)$ \\
Graduate & 0.894 & 0.539 & 1.250 & 1.074 \\
& $(2.798)$ & $(2.797)$ & $(2.815)$ & $(2.805)$ \\
Highways & -0.025 & -0.056 & 0.006 & -0.009 \\
& $(0.219)$ & $(0.207)$ & $(0.237)$ & $(0.228)$ \\
Airports & -0.002 & -0.002 & -0.002 & -0.002 \\
& $(0.022)$ & $(0.020)$ & $(0.023)$ & $(0.022)$ \\
& & & & \\
Observations & 1,133 & 1,133 & 1,133 & 1,133 \\
R-squared & 0.217 & 0.252 & 0.175 & 0.197 \\
FEs (1st stage Gravity) & No & $\mathrm{jt}$ & $\mathrm{jt} ; \mathrm{i}$ & $\mathrm{it} ; \mathrm{jt}$ \\
FEs Estimation & $\mathrm{t}, \mathrm{i}$ & $\mathrm{t}, \mathrm{i}$ & $\mathrm{t}, \mathrm{i}$ & $\mathrm{t}, \mathrm{i}$ \\
KP-test & 36.37 & 43.59 & 28.05 & 31.53 \\
Hansen J (p-value) & 0.0247 & 0.104 & 0.505 & 0.415 \\
\hline
\end{tabular}

Standard errors (in parenthesis) are robust to heteroscedasticity and arbitrary autocorrelation $* * * \mathrm{p}<0.01$, ${ }^{* *} \mathrm{p}<0.05,{ }^{*} \mathrm{p}<0.1$. In Migr /Pop instrumented using gravity prediction (Equation 13 , estimated using OLS) and the Policy instrument, constant not reported.

coefficient is always greater than 0.022 as our reference value from Table 2 discussed above.

In the same Table we also test for the consistency of our results across different specifications of the gravity equation from which we build our main instrument. In column (2) we add time varying country of origin fixed effects to control for all push factors that may influence migration patterns $\sqrt{29}$ Gravity specification is progressively enriched till column (4) where we include two-way time-varying fixed effects. ${ }^{30}$ Results are robust and stables, $\beta_{1}$ is always positive and statistically significant while the instrument is relevant and valid ${ }^{31}$

In Table 4 we report results for alternative measures of relative output at the province level. In column (1) we focus on the value added ratio of manufactures to financial services only, while in column (2) we consider the ratio with value added of retail services only in the denominator. In both cases previous evidence is confirmed along with IV diagnostics. In

\footnotetext{
${ }^{29} \overline{\text { Bertoli and Fernández-Huertas Moraga }}$ (2013) discuss the conditions under which one-way fixed effects are sufficient to control for multilateral resistance to migration (e.g., migrant have homogenous preferences across alternative locations).

${ }^{30}$ As noted before, fixed effect estimates from the first-stage regression are not used to build the instrument.

${ }^{31}$ see Table 12 in Appendix E for PPML based gravity instrument.
} 
column (3) to (5) we point to relative employment across same sectors and again we find large support of our findings.

Table 4: 2SLS Estimation, Robustness to Alternative Output Measures

\begin{tabular}{lcc|ccc}
\hline & $(1)$ & $(2)$ & $(3)$ & $(4)$ & $(5)$ \\
Dep. Var: & $\ln \left(V A_{m} / V A_{f}\right)$ & $\ln \left(V A_{m} / V A_{r}\right)$ & $\ln \left(E_{m} / E_{s}\right)$ & $\ln \left(E_{m} / E_{f}\right)$ & $\ln \left(E_{m} / E_{r}\right)$ \\
\hline & & & & & \\
lnMigr/Pop & $0.134^{* *}$ & $0.162^{* * *}$ & $0.116^{* *}$ & $0.122^{* *}$ & $0.106^{* *}$ \\
& $(0.056)$ & $(0.061)$ & $(0.053)$ & $(0.059)$ & $(0.054)$ \\
Density & -0.217 & 0.081 & $-0.331^{* *}$ & $-0.482^{* *}$ & $-0.233^{*}$ \\
& $(0.152)$ & $(0.130)$ & $(0.151)$ & $(0.218)$ & $(0.127)$ \\
Graduate & -3.366 & $5.978^{*}$ & -0.857 & $-7.080^{* *}$ & 3.553 \\
& $(2.915)$ & $(3.090)$ & $(2.613)$ & $(3.356)$ & $(2.460)$ \\
Highways & -0.075 & 0.004 & 0.174 & 0.113 & 0.193 \\
& $(0.170)$ & $(0.278)$ & $(0.224)$ & $(0.253)$ & $(0.208)$ \\
Airports & -0.005 & -0.002 & -0.001 & -0.015 & 0.003 \\
& $(0.018)$ & $(0.023)$ & $(0.015)$ & $(0.014)$ & $(0.014)$ \\
Observations & & & & & \\
Fixed Effects & 1,133 & 1,133 & 1,133 & 1,133 & 1,133 \\
KP-test & $\mathrm{t}, \mathrm{i}$ & $\mathrm{t}, \mathrm{i}$ & $\mathrm{t}, \mathrm{i}$ & $\mathrm{t}, \mathrm{i}$ & $\mathrm{t}, \mathrm{i}$ \\
Hansen J (p-value $)$ & 36.30 & 36.37 & 36.37 & 36.37 & 36.37 \\
\hline
\end{tabular}

Standard errors (in parenthesis) are robust to heteroscedasticity and arbitrary autocorrelation $* * * \mathrm{p}<0.01$, ** $\mathrm{p}<0.05,{ }^{*} \mathrm{p}<0.1$. Dependent variables: $V A_{f}$ financial services value added; $V A_{r}$ retail sector value added; $E_{m}$ total employment in manufactures; $E_{s}$ employment in services (excluding personal); $E_{f}$ employment in financial services; $E_{r}$ employment in retail sector. InMigr/Pop instrumented using gravity prediction (Equation 13 , estimated using OLS) and the Policy instrument, constant not reported.

\subsection{The Effect of Heterogeneous Migration}

In order to check whether the composition of migration at the province level plays a role in affecting the local production, we disaggregate foreign-born residents in province $i$ and time $t$ into three classes according to the characteristics of their origin countries.

As reported above, Italian immigration is characterized by a multitude of migrants in terms of countries of origin (189 nationalities in our sample period), so we aim at exploiting this additional variability of our sample. In particular, we assume that some characteristics of the countries of origin may approximate migrants' characteristics in terms of relative productivity when performing simple rather than complex tasks.

The theoretical model has shown that: the more similar the foreign-born residents to natives in terms of relative productivity of simple-to-complex tasks, the smaller the impact 
of a change in the migrants' share $f$ to the local production structure. However, we do not observe task productivity of each worker; so, a possible proxy may be the level of development of the origin country, as approximated by GDP per capita.

We are aware that GDP per capita is a very rough measure. Hence, we use it simply to rank the origin countries and create three classes of migrants with low, medium and high complex-to-simple-task productivity depending on their origin. By assuming that natives have a high relative productivity, the largest effect on the relative value added of manufacturing is expected when considering the migrants coming from countries with low per-capita GDP.

Furthermore, we employ a different classification of foreign-born residents according to their imputed schooling attainment. In particular, we use the information obtained by Docquier et al. (2008), who classify foreign-born residents in OECD countries by nationality and schooling attainment 23 For each province $i$ we consider the share of low-educated foreign workers aggregating the stock of migrants according to the source country share of primary school attainment 33 Figure 8 shows that, as expected, the two variables - GDP per capita and education attainment of the origin country of the migrants in Italy - are highly correlated.

From an empirical point of view the three different explanatory variables are obtained by segmenting the original migrants-to-natives ratio into three groups. This introduces a strong problem of multicollinearity since the three terciles are highly correlated 34

In columns (1)-(4) of Table 5 we present the results associated with the percentages of the different groups of migrants according to the income level of their origin country. More precisely, in Migr/Pop (Low) we consider only the migrants from the low-income countries, in Migr/Pop (High) those from high-income countries, in Migr/Pop (no High) those from low- and medium-income countries (excluding high-income) and in Migr/Pop (no Low) we

\footnotetext{
${ }^{32}$ Specifically, the stock (and rates) of migration inflows for each OECD country are provided by the level of schooling and gender for 195 source countries in 1990 and 2000.

${ }^{33}$ In such a way we do not exclude any nationality in building our education-specific variable, but we consider only the fraction of residents with a specific school attainment. Of course in doing so we implicitly assume that, by nationality, the distribution of migrants along the education attainment does not change province by province, but it is uniform over Italy, similarly to the previous case when we considered nationalities by the GDP per-capita.

${ }^{34}$ The correlation between the different couples of terciles for income ranges between 0.61 and 0.81 . The problem is much worse for schooling since the correlation coefficients are between 0.94 and 0.98 .
} 


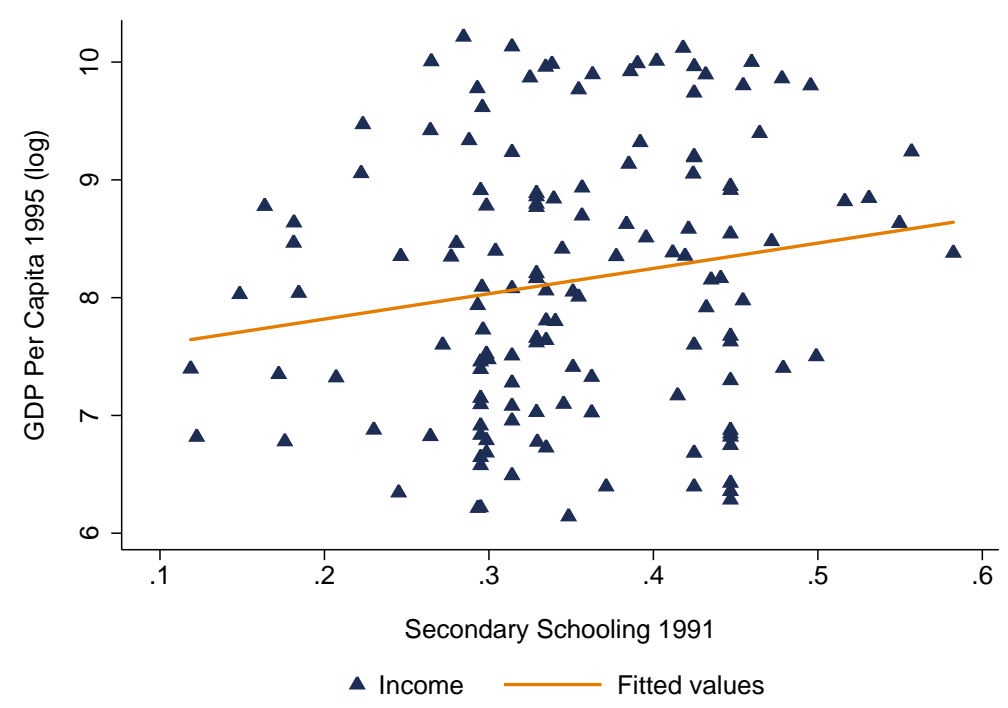

Figure 8: Correlation between per-capita GDP and level of schooling (vertical axis: log of GDP per capita of the country of origin; horizontal axis: fraction of migrants in Italy with secondary school degree from the same country of origin).

exclude migrants from the low-income countries. Similarly, in columns (5)-(8) we consider schooling attainment and the labels Low and High are referred respectively to primary-school attainment and tertiary-school attainment 35

Indeed, the positive effect of migrants on the relative value added of manufacturing appears to be magnified when we consider the composition by nationality of the foreign-born residents since aggregates that include more different migrants - both in a narrow way (i.e. only lowincome origins or primary-school attainment) and a wider way (i.e. excluding high-income origins or tertiary education) - show higher coefficients. The coefficients of columns (1) and (3) for income and (5) and (7) for schooling attainment are larger than when excluding lowincome origins or simply primary schooling attainment.

\footnotetext{
${ }^{35}$ More precisely, we include only one tercile at a time - see columns (1) and (2) for income, (5) and (6) for schooling - and when we exclude only one tercile - columns (3) and (4) for income, (7) and (8) for schooling. As also pointed out by a referee, when excluding one or more terciles we may encounter into the problem of omitted variables, but we still think this is a minor problem when excluding only one tercile since the terciles are highly correlated.
} 
Table 5: 2SLS Estimation: Heterogenous Effects

\begin{tabular}{|c|c|c|c|c|c|c|c|c|}
\hline \multirow{2}{*}{$\begin{array}{l}\text { Dep. Var: } \\
\ln \left(V A_{\text {man }} / V A_{\text {serv }}\right)\end{array}$} & (1) & (2) & $(3)$ & (4) & $(5)$ & (6) & $(7)$ & (8) \\
\hline & \multicolumn{4}{|c|}{ Income } & \multicolumn{4}{|c|}{ Schooling } \\
\hline ln Migr/Pop (Low) & $\begin{array}{c}0.106^{* *} \\
(0.050)\end{array}$ & & & & $\begin{array}{c}0.193^{* * *} \\
(0.064)\end{array}$ & & & \\
\hline ln Migr/Pop (High) & & $\begin{array}{c}0.098^{* *} \\
(0.045)\end{array}$ & & & & $\begin{array}{c}0.095^{* *} \\
(0.038)\end{array}$ & & \\
\hline ln Migr/Pop (no High) & & & $\begin{array}{c}0.160^{* *} \\
(0.063)\end{array}$ & & & & $\begin{array}{c}0.179^{* * *} \\
(0.061)\end{array}$ & \\
\hline ln Migr/Pop (no Low) & & & & $\begin{array}{c}0.125^{* * *} \\
(0.047)\end{array}$ & & & & $\begin{array}{c}0.126^{* * *} \\
(0.048)\end{array}$ \\
\hline Density & $\begin{array}{l}-0.103 \\
(0.142)\end{array}$ & $\begin{array}{c}0.096 \\
(0.097)\end{array}$ & $\begin{array}{l}-0.113 \\
(0.136)\end{array}$ & $\begin{array}{l}-0.033 \\
(0.110)\end{array}$ & $\begin{array}{l}-0.165 \\
(0.151)\end{array}$ & $\begin{array}{c}0.011 \\
(0.102)\end{array}$ & $\begin{array}{l}-0.134 \\
(0.140)\end{array}$ & $\begin{array}{l}-0.040 \\
(0.112)\end{array}$ \\
\hline Graduate & $\begin{array}{c}1.639 \\
(3.141)\end{array}$ & $\begin{array}{c}0.062 \\
(2.903)\end{array}$ & $\begin{array}{c}0.941 \\
(2.781)\end{array}$ & $\begin{array}{l}-0.143 \\
(2.800)\end{array}$ & $\begin{array}{l}1.080 \\
(2.818)\end{array}$ & $\begin{array}{c}0.597 \\
(2.843)\end{array}$ & $\begin{array}{l}1.069 \\
(2.800)\end{array}$ & $\begin{array}{l}0.943 \\
(2.816)\end{array}$ \\
\hline Highways & $\begin{array}{l}-0.105 \\
(0.185)\end{array}$ & $\begin{array}{l}-0.105 \\
(0.182)\end{array}$ & $\begin{array}{l}-0.045 \\
(0.218)\end{array}$ & $\begin{array}{l}-0.046 \\
(0.211)\end{array}$ & $\begin{array}{l}-0.017 \\
(0.230)\end{array}$ & $\begin{array}{l}-0.060 \\
(0.196)\end{array}$ & $\begin{array}{l}-0.017 \\
(0.228)\end{array}$ & $\begin{array}{l}-0.041 \\
(0.211)\end{array}$ \\
\hline Airports & $\begin{array}{l}-0.002 \\
(0.017)\end{array}$ & $\begin{array}{l}-0.004 \\
(0.017)\end{array}$ & $\begin{array}{l}-0.003 \\
(0.020)\end{array}$ & $\begin{array}{l}-0.002 \\
(0.021)\end{array}$ & $\begin{array}{l}-0.004 \\
(0.022)\end{array}$ & $\begin{array}{l}-0.003 \\
(0.019)\end{array}$ & $\begin{array}{l}-0.002 \\
(0.022)\end{array}$ & $\begin{array}{l}-0.001 \\
(0.021)\end{array}$ \\
\hline Observations & 1,133 & 1,133 & 1,133 & 1,133 & 1,133 & 1,133 & 1,133 & 1,133 \\
\hline R-squared & 0.286 & 0.298 & 0.208 & 0.308 & 0.175 & 0.280 & 0.189 & 0.246 \\
\hline FEs & $\mathrm{t}, \mathrm{i}$ & $\mathrm{t}, \mathrm{i}$ & $\mathrm{t} ; \mathrm{i}$ & $\mathrm{t} ; \mathrm{i}$ & $\mathrm{t}, \mathrm{i}$ & $\mathrm{t}, \mathrm{i}$ & $\mathrm{t} ; \mathrm{i}$ & t;i \\
\hline KP-test & 12.54 & 54.04 & 24.01 & 44.52 & 26.26 & 50.39 & 31.98 & 44.33 \\
\hline Hansen J (p-value) & 0.0403 & 0.107 & 0.0781 & 0.0405 & 0.0196 & 0.0450 & 0.0195 & 0.0267 \\
\hline
\end{tabular}

Standard errors (in parenthesis) are robust to heteroscedasticity and arbitrary autocorrelation $* * * \mathrm{p}<0.01$, ** $\mathrm{p}<0.05,{ }^{*} \mathrm{p}<0.1$. Column (1) and (2) Schooling Attainment for year 1991 from Docquier et al. (2008); Column (3) and (4) Income level (per-capita GDP) in year 1995 from World Bank - WDI. Low (High) refers to the lower (higher) tertile of the relative distribution. lnMigr/Pop instrumented using gravity prediction (Equation 13, estimated using OLS) and the Policy instrument, constant not reported. 


\section{Concluding remarks}

We have proposed a simple two-sector model with a common input (i.e. the mobile factor) and sector-specific inputs which are bundles of productive tasks. Tasks are supplied by heterogeneous workers - natives and foreign-born residents - who differ in terms of relative task productivity.

A reduced form can be obtained relating the relative output of the two sectors and the relative abundance of the two types of residents when assuming constant relative output prices. This relationship resembles the traditional Rybczynski equation.

The model is tested for Italy, i.e. a peculiar case where immigration has been rapid and very diverse. More exactly, we used the 103 Italian provinces in the period 1995-2006 and evaluated the impact of the increase in the foreign-born presence on the relative value added of manufactures with respect to the value added of services. By assuming that foreign-born residents had a comparative advantage in simple tasks and that manufactures are intensive in simple rather than complex tasks, we should observe a significant effect on the average provincial production structure in favor of manufacturing where immigration has been more intense.

Moreover, foreign-born residents are not all the same and we may find heterogeneity also among them. Italy is a very interesting case since its immigration has been highly diverse in terms of nationalities (189 nationalities have been present in 2006). We split the foreign-born residents in different sub-groups according the the level of GDP per capita and according to the education attainment of the different nationalities that arrived in Italy.

Quantitatively, our estimates show that ceteris paribus when doubling the presence of migrants over the total population induces a significant switch towards manufactures - between 13 and 19 per cent relative increase in value added in manufacturing with respect to services. When considering migrants from countries with low GDP per capita or simply primary-educated migrants - being the assignment of education distributed according to the nationality - our results can be considered as prima facie evidence and do not go against the model prediction. 


\section{References}

Accetturo, A., Bugamelli, M., and Lamorgese, A. (2012). Welcome to the machine: firms' reaction to low-skilled immigration. Temi di discussione (Economic working papers) 846, Bank of Italy, Economic Research and International Relations Area.

Altonji, J. and Card, D. (1991). The effects of immigration on the labor market outcomes of less-skilled natives. In Abowd, J. and Freeman, R., editors, Immigration, Trade and the Labor Market. University of Chicago Press.

Anderson, J. E. and van Wincoop, E. (2003). Gravity with gravitas: A solution to the border puzzle. American Economic Review, 93(1):170-192.

Bartolucci, F., Belotti, F., and Peracchi, F. (2005). Testing for time-invariant unobserved heterogeneity in generalized linear models for panel data. Journal of Econometrics, 184:111123.

Bertoli, S. and Fernández-Huertas Moraga, J. (2013). Multilateral resistance to migration. Journal of Development Economics, 102(C):79-100.

Bettin, G., Turco, A. L., and Maggioni, D. (2012). A firm-level perspective on migration. Development Working Papers 328, Centro Studi Luca d'Agliano, University of Milano.

Borjas, G. J. (2003). The labor demand curve is downward sloping: Reexamining the impact of immigration on the labor market. The Quarterly Journal of Economics, 118(4):1335-1374.

Borjas, G. J., Freeman, R. B., and Katz, L. (1996). Searching for the effect of immigration on the labor market. American Economic Review, 86(2):246-51.

Borjas, G. J. and Katz, L. F. (2007). The Evolution of the Mexican-Born Workforce in the United States, pages 13-56. University of Chicago Press.

Bratti, M., Benedictis, L., and Santoni, G. (2014). On the pro-trade effects of immigrants. Review of World Economics, pages 1-38. 
Briant, A., Combes, P.-P., and Lafourcade, M. (2010). Dots to boxes: Do the size and shape of spatial units jeopardize economic geography estimations? Journal of Urban Economics, $67: 287-302$.

Card, D. (2007). How Immigration Affects U.S. Cities. CReAM Discussion Paper, (11).

Card, D. and Lewis, E. G. (2007). The diffusion of mexican immigrants during the 1990s: Explanations and impacts. In Mexican Immigration to the United States, NBER Chapters, pages 193-228. National Bureau of Economic Research, Inc.

Combes, P.-P., Duranton, G., and Gobillon, L. (2011). The identification of agglomeration economies. Journal of Economic Geography, 11(2).

Corden, W. M. and Neary, J. P. (1982). Booming sector and de-industrialisation in a small open economy. Economic Journal, 92(368):825-48.

D'Amuri, F. and Peri, G. (2011). Immigration, jobs and employment protection: Evidence from europe. NBER Working Papers 17139, National Bureau of Economic Research, Inc.

D'Amuri, F. and Peri, G. (2012). Immigration, jobs and employment protection: evidence from europe before and during the great recession. Temi di discussione (Economic working papers) 886, Bank of Italy, Economic Research and International Relations Area.

D'Amuri, F. and Peri, G. (2014). Immigration, jobs and employment protection: evidence from europe before and during the great recession. Journal of the European Economic Association, (forthcoming).

D'Amuri, F. and Pinotti, P. (2010). Immigration and natives' labor market outcomes: evidence from italy. mimeo, Bank of Italy.

Docquier, F., Lowell, B. L., and Marfouk, A. (2008). A gendered assessment of the brain drain. Policy Research Working Paper Series 4613, The World Bank.

Dustmann, C. and Glitz, A. (2014). How Do Industries and Firms Respond to Changes in Local Labor Supply? Journal of Labor Economics, forthcoming. 
Feenstra, R. (2004). Advanced International Trade: Theory and Evidence. Princeton University Press.

Gandal, N., Hanson, G. H., and Slaughter, M. J. (2004). Technology, trade, and adjustment to immigration in israel. European Economic Review, 48(2):403-428.

Glitz, A. (2012). The labor market impact of immigration: A quasi-experiment exploiting immigrant location rules in germany. Journal of Labor Economics, 30(1):pp. 175-213.

González, L. and Ortega, F. (2011). How do very open economies adjust to large immigration flows? evidence from spanish regions. Labour Economics, 18(1):57-70.

Grossman, G. M. and Rossi-Hansberg, E. (2008). Trading tasks: A simple theory of offshoring. American Economic Review, 98(5):1978-97.

Hanson, G. H. and Slaughter, M. J. (2002). Labor-market adjustment in open economies: Evidence from us states. Journal of International Economics, 57(1):3-29.

Jayet, H., Ukrayinchuck, N., and DeArcangelis, G. (2010). The location of immigrants in italy : Disentangling networks and local effects. Annales d'Economie et de Statistique, (97-98):329-350.

Jones, R. W. (1971). A three factor model in theory, trade and history. In J. Bhagwati, R. Jones, R. M. and Vanek, J., editors, Trade, Balance of Payments and Growth. Amsterdam - North Holland.

Lewis, E. (2004). How did the Miami labor market absorb the Mariel immigrants? Technical report.

Lewis, E. (2011). Immigration, skill mix, and capital skill complementarity. The Quarterly Journal of Economics, 126(2):1029-1069.

Lewis, E. (2013). Immigration and production technology. Annual Review of Economics, $5: 165-191$. 
Mayer, T. and Zignago, S. (2011). Notes on CEPII's distances measures: The GeoDist database. Working papers, CEPII research center.

Okkerse, L. (2008). How to measure labour market effects of immigration: A review. Journal of Economic Surveys, 22(1):1-30.

Ortega, F. and Peri, G. (2014). Openness and income: The roles of trade and migration. Journal of International Economics, 92(2):231-251.

Ottaviano, G. I. P. and Peri, G. (2012). Rethinking the effect of immigration on wages. Journal of the European Economic Association, 10(1):152-197.

Peri, G. and Sparber, C. (2009). Task specialization, immigration, and wages. American Economic Journal: Applied Economics, 1(3):135-69.

Romalis, J. (2004). Factor Proportions and the Structure of Commodity Trade. American Economic Review, 94(1):67-97.

Santos Silva, J. and Tenreyro, S. (2006). The Log of Gravity. Review of Economics and Statistics, 88(4):641-658.

Wooldridge, J. (2010). Econometric Analysis of Cross Section and Panel Data. MIT Press, Cambridge, Massachusetts. 


\section{A Computation of Sectors' Task Complexity}

The construction of Figure 4 is based on the Tables below.

Table 6 is based on Table A3 in D'Amuri and Peri (2012) where the authors proposed a grouping of tasks for occupations. Besides the column rank, the score represents the percentile of workers performing less intensively that task. For instance, the first number 80 for Corporate Manager regarding Mental Tasks means that 80 percent of all workers is performing manual tasks less intensively than Corporate Managers.

In the last two columns we aggregate simple and non-simple/complex tasks by taking simple averages of the tasks in each group. Moreover, we compute simple averages for the 8 main groups of occupations (Corporate Mangers, Intellectual Occupations, Technical Occupations, Operative Occupations, Occupations Relative to Sales and Services, Specialized Workers, Conductors of Plants and Machinery Operators and Unskilled Workers).

For these 8 main groups we have data on the number of employees for each sector, as reported in Table 7. In order to obtain the aggregate score for each of the two sectors and the total economy, we weighted each one of the 8 occupation scores of Table 6 by the percentage of each type of occupation in the sector. For instance, Intellectual Professions with a score 70 for complex tasks have been included in the total computation of complex tasks with a weight equal to about 3 percent for Industry and 13.9 percent for Services, being 3 and 13.9 the percentages of workers reported doing Intellectual Professions respectively in Industry and Services.

Besides all the possible measurement errors that occur with the simple averaging, we ought to remind all the caution that were also reported in D'Amuri and Peri (2012). First of all, the scores (as percentiles) are all referred to the US labor market for the year 2000. 


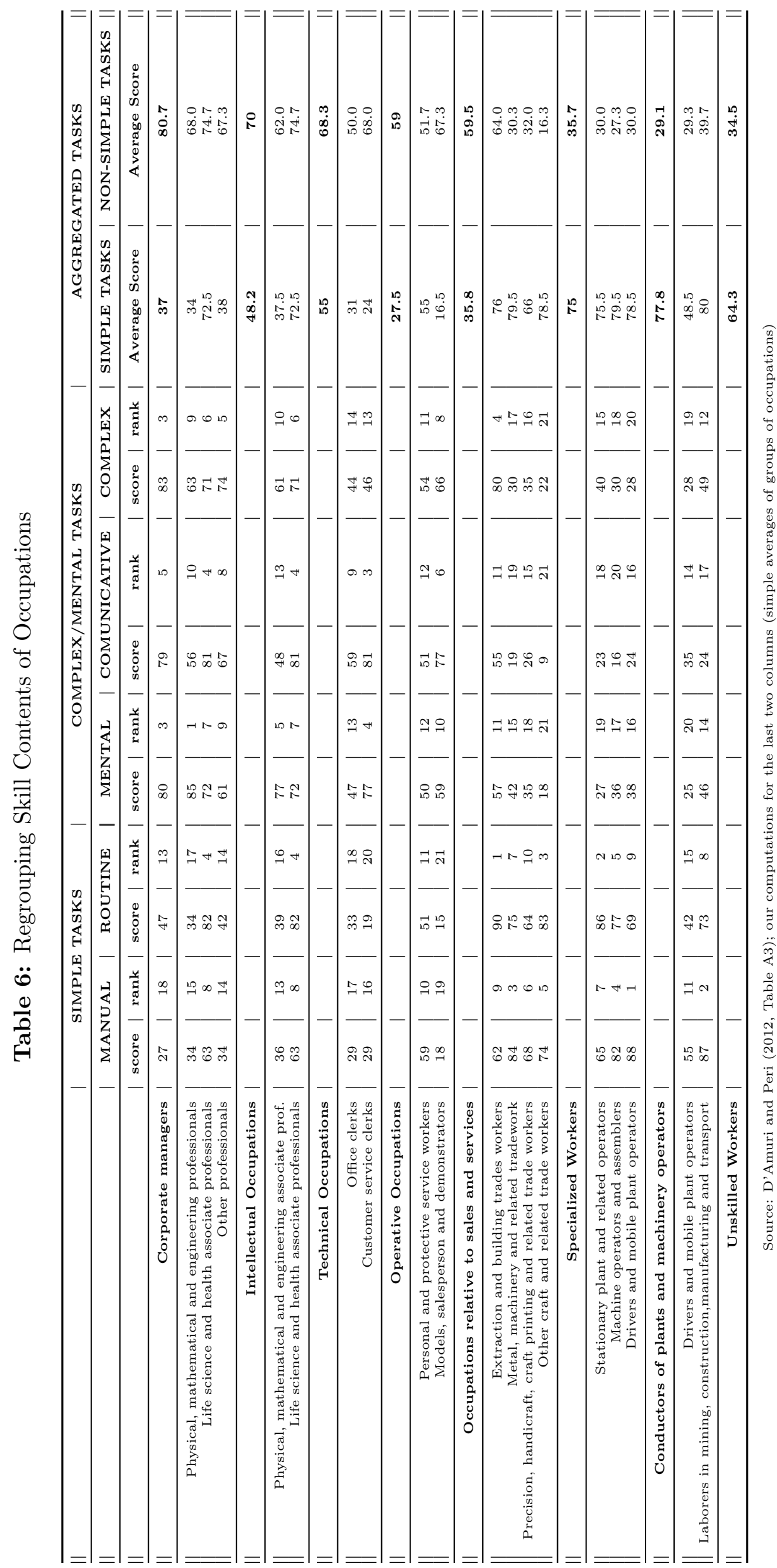


Table 7: Employment by occupation and by sector in 2005 (thousands)

\begin{tabular}{||c|c|c|c|c||}
\hline & Industry & Services & $\begin{array}{c}\text { TOTAL } \\
\text { (no Agriculture) }\end{array}$ & TOTAL \\
\hline Corporate managers & 296.5 & 630.5 & $\mathbf{9 2 7 . 0}$ & $\mathbf{1 0 4 0 . 5}$ \\
Intellectual Professions & 182.9 & 2043.4 & $\mathbf{2 2 2 6 . 3}$ & $\mathbf{2 2 3 0 . 8}$ \\
Technical Professions & 923.5 & 3473.1 & $\mathbf{4 3 9 6 . 6}$ & $\mathbf{4 4 1 8 . 7}$ \\
Operative Professions & 573.0 & 1987.5 & $\mathbf{2 5 6 0 . 5}$ & $\mathbf{2 5 8 1 . 1}$ \\
Specialized Workers & 2915.5 & 933.1 & $\mathbf{3 5 1 8 . 3}$ & $\mathbf{3 5 3 2 . 4}$ \\
Professions relative to sales and services & 173.1 & $\mathbf{3 8 4 8 . 7}$ & $\mathbf{4 3 0 0 . 2}$ \\
Conductors of plants and machinery operators & 1354.4 & 677.2 & $\mathbf{2 0 3 1 . 6}$ & $\mathbf{2 0 7 1 . 0}$ \\
Unskilled Workers & 274.7 & 1637.7 & $\mathbf{1 9 1 2 . 4}$ & $\mathbf{2 1 2 9 . 6}$ \\
TOTAL & 6693.7 & 14727.7 & $\mathbf{2 1 4 2 1 . 4}$ & $\mathbf{2 2 3 0 4 . 2}$ \\
\hline
\end{tabular}

Source: ISTAT and ISFOL Elaborations on Labor Force Survey (2007).

The computation of the indexes presented in Figure 4 is the following:

$$
Z^{k}=\sum_{i=1}^{n} w_{i}^{k} Z_{i}
$$

where $n$ is the number of occupations, $w_{i}^{k}$ is the weight of occupation $i$ in sector $k(k=I, V, T$ $I$ for Industry, $V$ for Services, $T$ for Total Economy) $-w_{i}^{k}=\frac{o c c_{i}^{k}}{\sum_{i=1}^{n} o c c_{i}^{k}}$ occ stays for employment - $Z_{i}$ is the index of type-of-task $Z$ ( $Z=C, S C$ fo Complex, $S$ for Simple) for occupation $i$ and $Z^{k}$ is the index of type-of-task $Z$ for sector $k$.

It is easy to show that $Z^{T} \in\left(Z^{I}, Z^{V}\right)$ since $w_{i}^{T}=w_{i}^{I} q^{I}+w_{i}^{V} q^{V}$ where $q^{k}=\frac{\sum_{i=1}^{n} o c c_{i}^{k}}{\sum_{i=1}^{n} o c c_{i}^{T}}$ and $q^{V}=1-q^{I}$.

Note also that:

$$
\frac{C^{T}}{S^{T}}=\frac{q^{I} C^{I}+q^{V} C^{V}}{q^{I} S^{I}+q^{V} S^{V}}
$$

Since the index of task complexities of the two sectors are very close to be complementary (although not required by the computations), this is the reason why the ratio of complex-tosimple task for the whole economy is close to 1 in Figure 4.

\section{B Redistribution and Welfare}

The inflow of foreign-born residents has an effect also in the market of the (within-area) mobile factor $H$. In particular, the rise in $f$ induces an increase in the relative demand for the mobile 
factor $H$ from sector $M$. As shown in Figure 9, the upward shift from $V M P H_{M}$ to $V M P H_{M}^{\prime}$ implies that employment of the mobile factor in sector $M$ increases $-H_{M}$ rises. Since the quantity of mobile factor is given, employment of this factor must decrease in the $V$ sector $H_{V}$ lowers.

Overall, the inflow of migrants represents an increase in resources that alters the quantities in the specific factors. Given the constant returns to scale technology in both sectors, the mobile factor becomes scarcer and its nominal "wage" increases. In Figure 9 the upward shift in the $V M P H_{M}$ schedule causes also the rise from $W_{H}^{0}$ to $W_{H}^{\prime}$.

Hence, although the hypothesis of constant output relative prices implies a constant ratio in the relative wage for the specific composite factors of the two sectors, the model can still envisage a redistribution effect. Indeed, the mobile factor $H$ becomes scarcer and its remuneration increases not only in nominal and real terms, but also in relative terms with respect to the remuneration of the specific factors.

This is a well-known effect in the traditional specific-factor model. In our framework there is a redistribution effect in favor of the mobile factor, which gains from migration.

When measuring welfare as directly proportional to the wage ${ }^{36}$ it is easy to show that total welfare in the economy increases since the wage of the mobile factor $H$ increases, natives are not affected and the new foreign-born residents are likely to gain a higher wage than at the origin.

\footnotetext{
${ }^{36}$ In fact D'Amuri and Peri $(2012)$ consider a very similar optimization problem as utility maximization.
} 


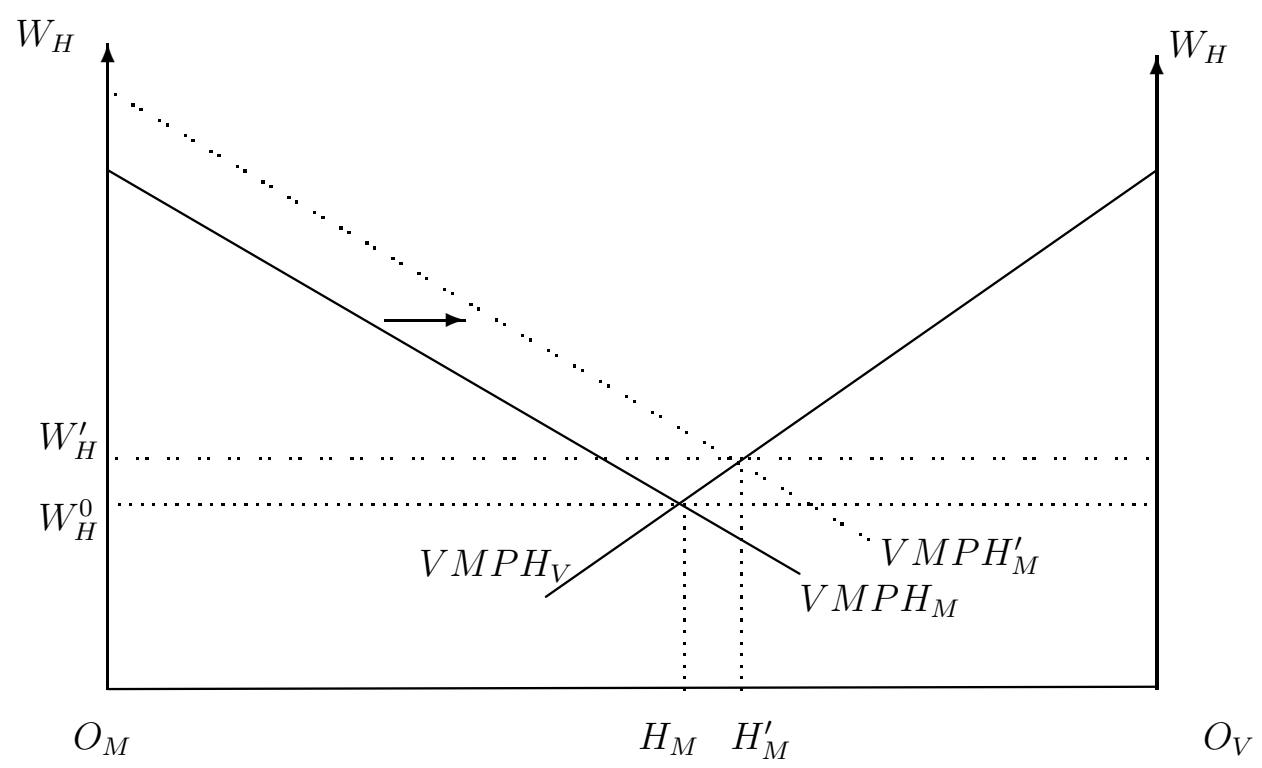

Figure 9: Effect of the increase in the $f$ in the market of the "mobile" factor $H$. 


\section{Relationship between Relative Wage of Composite Factors and Relative Compensation of Tasks}

From the CES characteristics, the "wage" of each composite factor is the following:

$$
W_{j}=\left[\beta_{j} W_{S}^{1-\sigma}+\left(1-\beta_{j}\right) W_{C}^{1-\sigma}\right]^{\frac{1}{1-\sigma}}
$$

for $j=M, V$. Let us define $\omega \equiv \frac{W_{C}}{W_{S}}$. So:

$$
\frac{W_{M}}{W_{V}}=\left[\frac{\beta_{M}+\left(1-\beta_{M}\right) \omega^{1-\sigma}}{\beta_{V}+\left(1-\beta_{V}\right) \omega^{1-\sigma}}\right]^{\frac{1}{1-\sigma}}
$$

Let us define $W \equiv\left(\frac{W_{M}}{W_{V}}\right)^{\sigma-1}$ and $\widetilde{\omega} \equiv \omega^{\sigma-1}$. Hence:

$$
W=\frac{\beta_{V} \widetilde{\omega}+\left(1-\beta_{V}\right)}{\beta_{M} \widetilde{\omega}+\left(1-\beta_{M}\right)}
$$

and this implies:

$$
\widetilde{\omega}=\frac{\left(1-\beta_{M}\right) W-\left(1-\beta_{V}\right)}{\beta_{V}-W \beta_{M}}
$$

As expected, when the relative price of output is given, then not only the relative "wage" of the two specific composite factors is given, but also the relative "wage" of the two types of labor services that form the composite labor factors.

Moreover, the relative wage $\omega \equiv \frac{W_{C}}{W_{S}}$ decreases when $W$ increases, hence when $\frac{p_{M}}{p_{V}}$ increases.

A final observation on the determination of the relative wage $\omega$ concerns the condition of economically meaningful value, i.e. for $\omega>0$. In order for $\omega$ to take a positive value, we need a condition on the relative wage of the composite factors, which implies a condition on the relative output price:

$$
\frac{\beta_{V}}{\beta_{M}}<\left(\frac{W_{M}}{W_{V}}\right)^{\sigma-1}<\frac{1-\beta_{V}}{1-\beta_{M}}
$$

or 


$$
\frac{\beta_{V}}{\beta_{M}}<\left(\frac{p_{M}}{p_{V}}\right)^{\frac{\sigma-1}{\alpha}}<\frac{1-\beta_{V}}{1-\beta_{M}}
$$

where, we recall, $\beta_{M}>\beta_{V}$.

\section{Including a Non-Traded Sector}

The model presented in the text can be easily extended to include a nontraded sector (e.g. construction or personal services) besides two traded sectors (e.g. manufacturing and financial services). When assuming the small-economy assumption, the relative price of the two traded goods can be considered as given and they can be aggregated into a single Hicksian composite traded good following Corden and Neary (1982). The real exchange rate is then the relative price between the nontraded good and the composite traded good.

Let us borrow the same model as in Corden and Neary (1982), but let us perform a different exercise in comparative statics from them: Corden and Neary (1982) are interested in showing the effect of a boom in one of the two traded sectors (in particular, the extractive sector and explaining the 'Dutch disease'), whereas we want to see the effect of immigration as a change in the relative endowment of simple to complex performing tasks.

Let us assume that in terms of usage of simple versus complex tasks, the nontraded sector $N T$ is less simple-task intensive than one of the two traded goods - sector $M$ manufacturing - but more simple-task intensive than the other - the sector $V$ in the text of traded services.

Corden and Neary (1982) separate the resource movement effect - when keeping constant the real exchange rate - from the spending effect - when considering also the demand side with standard preferences. As in their case, the spending effect reinforces the first effect without ambiguity on what happens traded services. Figure 10 illustrates the resource movement effect.

Similarly to Figure 9, Figure 10 represents the market for factor $H$, which is in fixed supply in the province. The downward sloping line $V M P H_{T}$ represents the value of the marginal product of factor $H$ for the composite traded sector or the demand for the fixed factor $H$ 


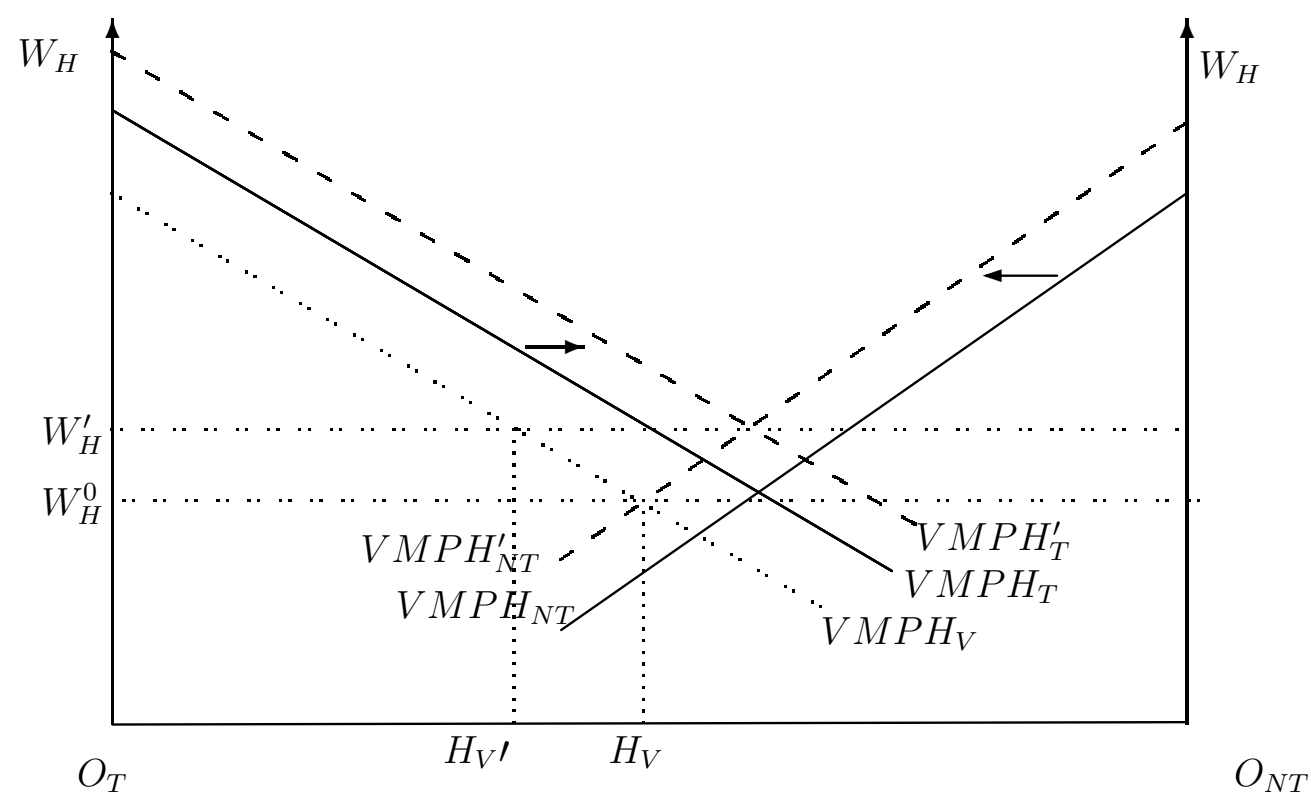

Figure 10: Effect of the increase in the $f$ in the market of the "mobile" factor $H$ with a traded and a nontraded sector.

from $T$. The line $V M P H_{V}$ is equivalently the demand for factor $H$ from the service sector $V$, i.e. the least simple-task intensive sector. The other thick curve $V M P H_{N T}$ is the demand for factor $H$ from the nontraded sector $N T$. The initial equilibrium is determined at the wage $W_{H}^{0}$.

Immigration raises the relative endowment of performable simple tasks with respect to complex tasks. Hence, there is a relative increase in the demand for factor $H$ from the two most simple-task intensive sectors. Graphically, this means a shift from $V M P H_{N T}$ to $V M P H_{N T}^{\prime}$ for the nontraded sector and from $V M P H_{T}$ to $V M P H_{T}^{\prime}$ in the traded sector, but no change in to $V M P H_{V}$, being $V$ a sort of reference sector.

As a consequence, the wage for factor $H$ increases and, if the shift in the demand for $H$ from the traded sector is larger than for the nontraded sector, there is a relative increase in the traded sector with respect to the nontraded sector. This is equivalent to the resource movement effect in Corden and Neary (1982).

Without ambiguity there is a relative contraction in the $V$ sector since the demand $V M P H_{V}$ does not move and there is an increase in the wage of factor $H$. This is repre- 
sented in Figure 10 with a contraction in the mobile factor employed in sector $V$ from $H_{V}$ to $H_{V}^{\prime}$

If there are no inferior goods, the increase in income determined by the increase in resources due to immigration will raise the demand for both the nontraded and the traded goods, but if there is a contraction in the relative supply of the nontraded good its relative price increases, i.e. we have a real exchange rate appreciation. Graphically, this will induce a further shift to the left of the demand for $H$ from the nontraded sector and a further increase in the wage for $H$ (not reported in the Figure 10). Unambiguously, there is more contraction in sector $V$.

In terms of the two traded sectors - that are the traded sectors we analyzed in the text and for which we provide empirical evidence - there is no ambiguity on the relative effect. Also the model with a nontraded sector shows a relative contraction in the service sector with respect to manufacturing.

\section{E Other Robustness Checks in Estimation}

Tables 810 are a new version of the Tables 35 when the 2SLS estimation is performed only with the gravity instrument and excluding the policy instrument. The results are always significant and the coefficient of our variable of interest is even higher than before. The new range is $13-23$ per cent increase in the relative value added of manufacturing when the migration presence doubles.

Table 11 and 12 report the first-stage gravity estimation using respectively OLS (log of positive values of the dependent variable) and Pseudo Poisson Maximum Likelihood (PPML). This latter estimation takes all values, including zeros, of the dependent variable in levels to account for the incidence of zeros and errors heteroscedasticity.

Both tables show that the results of the estimation are very stable independently of the different specifications. In particular, the model in column (3) includes the province fixed effect and the results mimic the case in which we would adjust the Card regressor $-\ln (M i g)_{i j}^{1991}$ with the province population. We ought to notice that the estimates do not change much. 
Table 8: 2SLS Estimation, Province Fixed Effects

\begin{tabular}{lcccc}
\hline & $(1)$ & $(2)$ & $(3)$ & $(4)$ \\
Dep. Var: & \multicolumn{4}{c}{$\ln \left(V A_{\text {man }} / V A_{\text {serv }}\right)$} \\
\hline \multirow{2}{*}{ lnMigr/Pop } & $0.233^{* * *}$ & $0.167^{* *}$ & $0.185^{* *}$ & $0.184^{* *}$ \\
& $(0.083)$ & $(0.072)$ & $(0.073)$ & $(0.073)$ \\
Density & -0.182 & -0.108 & -0.128 & -0.127 \\
& $(0.160)$ & $(0.139)$ & $(0.144)$ & $(0.144)$ \\
Graduate & 1.819 & 1.012 & 1.237 & 1.226 \\
& $(2.896)$ & $(2.815)$ & $(2.813)$ & $(2.812)$ \\
Highways & 0.055 & -0.015 & 0.005 & 0.004 \\
& $(0.260)$ & $(0.228)$ & $(0.236)$ & $(0.236)$ \\
Airports & -0.002 & -0.002 & -0.002 & -0.002 \\
& $(0.025)$ & $(0.022)$ & $(0.023)$ & $(0.023)$ \\
& & & & \\
Observations & 1,133 & 1,133 & 1,133 & 1,133 \\
Fixed Effects & $\mathrm{t} ; \mathrm{i}$ & $\mathrm{t} ; \mathrm{i}$ & $\mathrm{t} ; \mathrm{i}$ & $\mathrm{t} ; \mathrm{i}$ \\
KP-test & 40.33 & 60.11 & 55.88 & 56.21 \\
\hline
\end{tabular}

Standard errors (in parenthesis) are robust to heteroscedasticity and arbitrary autocorrelation $* * * \mathrm{p}<0.01$, ${ }^{* *} \mathrm{p}<0.05,{ }^{*} \mathrm{p}<0.1$. In Migr/Pop instrumented using gravity prediction (Equation 13 , estimated using OLS), constant not reported.

Table 9: 2SLS Estimation, Robustness to Alternative Output Measures

\begin{tabular}{lcc|ccc}
\hline & $(1)$ & $(2)$ & $(3)$ & $(4)$ & $(5)$ \\
Dep. Var: & $\ln \left(V A_{m} / V A_{f}\right)$ & $\ln \left(V A_{m} / V A_{r}\right)$ & $\ln \left(E_{m} / E_{s}\right)$ & $\ln \left(E_{m} / E_{f}\right)$ & $\ln \left(E_{m} / E_{r}\right)$ \\
\hline \multirow{2}{*}{ lnMigr/Pop } & $0.243^{* * *}$ & $0.225^{* * *}$ & $0.149^{* *}$ & $0.181^{* *}$ & $0.128^{*}$ \\
& $(0.085)$ & $(0.087)$ & $(0.076)$ & $(0.085)$ & $(0.076)$ \\
Density & $-0.339^{*}$ & 0.010 & $-0.367^{* *}$ & $-0.548^{* *}$ & $-0.257^{*}$ \\
& $(0.198)$ & $(0.150)$ & $(0.171)$ & $(0.249)$ & $(0.146)$ \\
Graduate & -2.042 & $6.750^{* *}$ & -0.460 & $-6.363^{*}$ & 3.824 \\
& $(3.057)$ & $(3.158)$ & $(2.687)$ & $(3.490)$ & $(2.518)$ \\
Highways & 0.040 & 0.070 & 0.208 & 0.175 & 0.216 \\
& $(0.226)$ & $(0.311)$ & $(0.244)$ & $(0.283)$ & $(0.224)$ \\
Airports & -0.005 & -0.002 & -0.001 & -0.014 & 0.003 \\
& $(0.023)$ & $(0.026)$ & $(0.017)$ & $(0.017)$ & $(0.015)$ \\
Observations & 1,133 & & & & 1,133 \\
Fixed Effects & $\mathrm{t} ; \mathrm{i}$ & 1,133 & 1,133 & $\mathrm{t}$ & 1,133 \\
KP-test & 40.33 & $\mathrm{t} ; \mathrm{i}$ & $\mathrm{t} ; \mathrm{i}$ & $\mathrm{t} ; \mathrm{i}$ & 40.33 \\
\hline
\end{tabular}

Standard errors (in parenthesis) are robust to heteroscedasticity and arbitrary autocorrelation $* * * \mathrm{p}<0.01$, ** $\mathrm{p}<0.05{ }^{*} \mathrm{p}<0.1$. Dependent variables: $V A_{f}$ financial services value added; $V A_{r}$ retail sector value added; $E_{m}$ total employment in manufactures; $E_{s}$ employment in services (excluding personal); $E_{f}$ employment in financial services; $E_{r}$ employment in retail sector. lnMigr/Pop instrumented using gravity prediction (Equation 13, estimated using OLS), constant not reported. 
Table 10: 2SLS Estimation: Heterogenous Effects

\begin{tabular}{|c|c|c|c|c|c|c|c|c|}
\hline $\begin{array}{l}\text { Dep. Var: } \\
\ln \left(V A_{\text {man }} / V A_{\text {serv }}\right)\end{array}$ & \multicolumn{3}{|c|}{ Income } & (4) & $(5)$ & $\begin{array}{l}\text { (6) } \\
\text { Sch }\end{array}$ & $\begin{array}{l}\text { (7) } \\
\text { oling }\end{array}$ & (8) \\
\hline ln Migr/Pop (Low) & $\begin{array}{c}0.149^{* *} \\
(0.061)\end{array}$ & & & & $\begin{array}{c}0.289^{* * *} \\
(0.097)\end{array}$ & & & \\
\hline ln Migr/Pop (High) & & $\begin{array}{c}0.135^{* *} \\
(0.059)\end{array}$ & & & & $\begin{array}{r}0.147^{* *} \\
(0.059)\end{array}$ & & \\
\hline ln Migr/Pop (no High) & & & $\begin{array}{c}0.226^{* *} \\
(0.093)\end{array}$ & & & & $\begin{array}{c}0.264^{* * *} \\
(0.090)\end{array}$ & \\
\hline $\ln$ Migr/Pop (no Low) & & & & $\begin{array}{c}0.247^{* *} \\
(0.105)\end{array}$ & & & & $\begin{array}{c}0.195^{* * *} \\
(0.074)\end{array}$ \\
\hline Density & $\begin{array}{l}-0.177 \\
(0.159)\end{array}$ & $\begin{array}{c}0.103 \\
(0.099)\end{array}$ & $\begin{array}{c}-0.192 \\
(0.171)\end{array}$ & $\begin{array}{l}-0.142 \\
(0.163)\end{array}$ & $\begin{array}{l}-0.285 \\
(0.200)\end{array}$ & $\begin{array}{c}-0.026 \\
(0.111)\end{array}$ & $\begin{array}{l}-0.234 \\
(0.179)\end{array}$ & $\begin{array}{l}-0.104 \\
(0.134)\end{array}$ \\
\hline Graduate & $\begin{array}{c}2.712 \\
(3.302)\end{array}$ & $\begin{array}{l}0.478 \\
(2.928)\end{array}$ & $\begin{array}{l}1.754 \\
(2.872)\end{array}$ & $\begin{array}{c}0.707 \\
(2.941)\end{array}$ & $\begin{array}{l}2.121 \\
(2.992)\end{array}$ & $\begin{array}{l}1.479 \\
(2.895)\end{array}$ & $\begin{array}{l}2.058 \\
(2.936)\end{array}$ & $\begin{array}{l}2.002 \\
(2.910)\end{array}$ \\
\hline Highways & $\begin{array}{l}-0.071 \\
(0.203)\end{array}$ & $\begin{array}{l}-0.072 \\
(0.192)\end{array}$ & $\begin{array}{c}0.015 \\
(0.258)\end{array}$ & $\begin{array}{c}0.095 \\
(0.284)\end{array}$ & $\begin{array}{c}0.069 \\
(0.281)\end{array}$ & $\begin{array}{c}0.011 \\
(0.223)\end{array}$ & $\begin{array}{c}0.065 \\
(0.275)\end{array}$ & $\begin{array}{c}0.039 \\
(0.249)\end{array}$ \\
\hline Airports & $\begin{array}{l}-0.002 \\
(0.018)\end{array}$ & $\begin{array}{l}-0.005 \\
(0.018)\end{array}$ & $\begin{array}{l}-0.003 \\
(0.023)\end{array}$ & $\begin{array}{l}-0.002 \\
(0.027)\end{array}$ & $\begin{array}{l}-0.004 \\
(0.027)\end{array}$ & $\begin{array}{l}-0.003 \\
(0.022)\end{array}$ & $\begin{array}{l}-0.002 \\
(0.027)\end{array}$ & $\begin{array}{l}-0.001 \\
(0.024)\end{array}$ \\
\hline $\begin{array}{l}\text { Observations } \\
\text { FEs }\end{array}$ & $\begin{array}{c}1,133 \\
\mathrm{t}: \mathrm{i}\end{array}$ & $\begin{array}{c}1,133 \\
\text { t:i }\end{array}$ & $\begin{array}{c}1,133 \\
t: j\end{array}$ & $\begin{array}{c}1,133 \\
\text { t:j }\end{array}$ & $\begin{array}{c}1,133 \\
\text { t:j }\end{array}$ & $\begin{array}{c}1,133 \\
\text { t:j }\end{array}$ & $\begin{array}{c}1,133 \\
\text { t:j }\end{array}$ & $\begin{array}{c}1,133 \\
\text { t:i }\end{array}$ \\
\hline $\begin{array}{l}\text { FEs } \\
\text { KP-test }\end{array}$ & $\begin{array}{c}t ; i \\
14.93\end{array}$ & $\begin{array}{c}\mathrm{t} ; \mathrm{i} \\
73.75\end{array}$ & $\begin{array}{c}t ; j \\
26.29\end{array}$ & $\begin{array}{c}\text { t;j } \\
37.87\end{array}$ & $\begin{array}{c}t ; 1 \\
26.12\end{array}$ & $\begin{array}{l}\mathrm{t} ; 1 \\
59.17\end{array}$ & 34.70 & $\begin{array}{c}\text { t;1 } \\
51.36\end{array}$ \\
\hline
\end{tabular}

Standard errors (in parenthesis) are robust to heteroscedasticity and arbitrary autocorrelation $* * * \mathrm{p}<0.01$, ${ }^{* *} \mathrm{p}<0.05,{ }^{*} \mathrm{p}<0.1$. Column (1) and (2) Schooling Attainment for year 1991 from Docquier et al. (2008); Column (3) and (4) Income level (per-capita GDP) in year 1995 from World Bank - WDI. Low (High) refers to the lower (higher) tertile of the relative distribution. InMigr/Pop instrumented using gravity prediction (Equation 13 , estimated using OLS), constant not reported. 
Table 11: First-Stage Gravity Model of Bilateral Migration Flows: OLS Estimation

\begin{tabular}{|c|c|c|c|c|}
\hline \multirow{3}{*}{$\frac{\text { Dep. Var: }}{\ln (\text { DIST })_{i j}^{k m}}$} & (1) & (2) & (3) & (4) \\
\hline & \multicolumn{4}{|c|}{$\ln M i g /$ Pop $_{i j t}\left(M i g /\right.$ Pop $\left._{i j t}>0\right)$} \\
\hline & $\begin{array}{c}-0.517^{* * *} \\
(0.013)\end{array}$ & $\begin{array}{c}-0.494^{* * *} \\
(0.056)\end{array}$ & $\begin{array}{c}-0.416^{* * *} \\
(0.048)\end{array}$ & $\begin{array}{c}-0.414^{* * *} \\
(0.048)\end{array}$ \\
\hline $\ln (\mathrm{STOCK})_{i j}^{1991}$ & $\begin{array}{c}0.617^{* * *} \\
(0.007)\end{array}$ & $\begin{array}{c}0.622^{* * *} \\
(0.008)\end{array}$ & $\begin{array}{c}0.546^{* * *} \\
(0.010)\end{array}$ & $\begin{array}{c}0.550^{* * *} \\
(0.010)\end{array}$ \\
\hline BORDER $_{i j}$ & $\begin{array}{c}0.179 \\
(0.164)\end{array}$ & $\begin{array}{c}0.631^{* * *} * \\
(0.201)\end{array}$ & $\begin{array}{c}0.696^{* * *} \\
(0.199)\end{array}$ & $\begin{array}{c}0.692^{* * *} * \\
(0.198)\end{array}$ \\
\hline $\ln (\mathrm{POP})_{j t}$ & $\begin{array}{c}-0.463^{* * *} \\
(0.018)\end{array}$ & $\begin{array}{c}-0.378^{* * *} \\
(0.015)\end{array}$ & $\begin{array}{c}0.718^{* * *} \\
(0.106)\end{array}$ & \\
\hline $\ln (\mathrm{AREA})_{j}$ & $\begin{array}{c}-0.210^{* * *} \\
(0.017)\end{array}$ & $\begin{array}{c}-0.229^{* * *} * \\
(0.013)\end{array}$ & & \\
\hline $\ln (\mathrm{AREA})_{i}$ & $\begin{array}{c}-0.061^{* * *} \\
(0.007)\end{array}$ & & & \\
\hline $\ln (\mathrm{POP})_{i t}$ & $\begin{array}{c}0.288^{* * *} \\
(0.010)\end{array}$ & & & \\
\hline COLONY ${ }_{i j}^{e v e r}$ & $\begin{array}{c}0.123 \\
(0.086)\end{array}$ & & & \\
\hline LANGUAGE $_{i j}^{e t h n o}$ & $\begin{array}{c}-0.693^{* * *} \\
(0.087)\end{array}$ & & & \\
\hline LANDLOCKED $_{i}$ & $\begin{array}{c}-0.189^{* * *} \\
(0.032)\end{array}$ & & & \\
\hline Observations & 131,570 & 132,709 & 132,709 & 132,709 \\
\hline R-squared & 0.575 & 0.779 & 0.818 & 0.824 \\
\hline FEs & No & it & it ; j & it ; jt \\
\hline
\end{tabular}

Standard errors in parentheses clustered by country pairs, ${ }^{* * *} \mathrm{p}<0.01, * * \mathrm{p}<0.05,{ }^{*} \mathrm{p}<0.1$. Dependent variable is the log of the ratio of bilateral migration from Country $i$ to Province $j$ to population in Province $j$ at time $t$ excluding zero values. Note that Italy share a common language only with Switzerland, while only Eritrea, Libya and Somalia where former colonies; we keep Language ${ }_{i j}^{e t h n o}$ and Colony ${ }_{i j}^{e v e r}$ only in Column (1) to avoid spurious identification of the parameter when fixed effects are included. All regressions include a constant, not reported. 
Table 12: First-Stage Gravity Model of Bilateral Migration Flows: PPML Estimation

\begin{tabular}{|c|c|c|c|c|}
\hline \multirow{3}{*}{$\frac{\text { Dep. Var: }}{\ln (\text { DIST })_{i j}^{k m}}$} & (1) & $(2)$ & (3) & (4) \\
\hline & \multicolumn{4}{|c|}{ Mig/Pop } \\
\hline & $\begin{array}{c}-0.419^{* * *} \\
(0.027)\end{array}$ & $\begin{array}{c}0.104 \\
(0.102)\end{array}$ & $\begin{array}{l}-0.124 \\
(0.082)\end{array}$ & $\begin{array}{c}-0.142^{*} \\
(0.078)\end{array}$ \\
\hline $\ln (\mathrm{STOCK})_{i j}^{1991}$ & $\begin{array}{c}0.605^{* * *} \\
(0.016)\end{array}$ & $\begin{array}{c}0.592^{* * *} \\
(0.023)\end{array}$ & $\begin{array}{c}0.683^{* * *} \\
(0.028)\end{array}$ & $\begin{array}{c}0.681^{* * *} \\
(0.027)\end{array}$ \\
\hline BORDER $_{i j}$ & $\begin{array}{l}-0.018 \\
(0.155)\end{array}$ & $\begin{array}{c}1.239^{* * *} \\
(0.175)\end{array}$ & $\begin{array}{c}0.823^{* * *} \\
(0.109)\end{array}$ & $\begin{array}{c}0.798^{* * *} \\
(0.106)\end{array}$ \\
\hline $\ln (\mathrm{POP})_{j t}$ & $\begin{array}{c}-0.272^{* * *} \\
(0.057)\end{array}$ & $\begin{array}{c}-0.253^{* * *} \\
(0.038)\end{array}$ & $\begin{array}{c}2.502^{* * *} \\
(0.396)\end{array}$ & \\
\hline $\ln (\mathrm{AREA})_{j}$ & $\begin{array}{c}-0.312^{* * *} \\
(0.036)\end{array}$ & $\begin{array}{c}-0.303^{* * *} \\
(0.055)\end{array}$ & & \\
\hline $\ln (\mathrm{AREA})_{i}$ & $\begin{array}{c}-0.040^{* *} \\
(0.018)\end{array}$ & & & \\
\hline $\ln (\mathrm{POP})_{i t}$ & $\begin{array}{c}0.139^{* * *} \\
(0.038)\end{array}$ & & & \\
\hline COLONY & $\begin{array}{c}-0.560^{* * *} \\
(0.134)\end{array}$ & & & \\
\hline LANGUAGE $_{i j}^{\text {ethno }}$ & $\begin{array}{c}-1.223^{* * *} \\
(0.162)\end{array}$ & & & \\
\hline LANDLOCKED $_{i}$ & $\begin{array}{c}-0.385^{* * *} \\
(0.107)\end{array}$ & & & \\
\hline Observations & 174,100 & 176,771 & 176,771 & 176,771 \\
\hline R-squared & 0.282 & 0.513 & 0.650 & 0.667 \\
\hline FEs & No & it & it $; j$ & it ; jt \\
\hline
\end{tabular}

Standard errors in parentheses clustered by country pairs, ${ }^{* * *} \mathrm{p}<0.01, * * \mathrm{p}<0.05,{ }^{*} \mathrm{p}<0.1$. Dependent variable is the ratio of bilateral migration from Country $i$ to Province $j$ to population in Province $j$ at time $t$ including zero values. Note that Italy share a common language only with Switzerland, while only Eritrea, Libya and Somalia where former colonies; we keep Language $_{i j}^{\text {ethno }}$ and Colony ${ }_{i j}^{\text {ever }}$ only in Column (1) to avoid spurious identification of the parameter when fixed effects are included. All regressions include a constant, not reported. 
Table 13 reports the second-stage estimation results, as in Table 3, but using the instrument obtained from the PPML first-stage regression (Table 12). Also in this case the estimates are very stable and similar to the ones obtained when using OLS in the first stage.

Table 13: 2SLS Estimation, Province Fixed Effects (1st-Stage Gravity Estimated by PPML)

\begin{tabular}{lcccc}
\hline & $(1)$ & $(2)$ & $(3)$ & $(4)$ \\
Dep. Var: & \multicolumn{5}{c}{$\ln \left(V A_{\text {man }} / V A_{\text {serv }}\right)$} \\
\hline ln Migr/Pop & $0.135^{* *}$ & $0.125^{* *}$ & $0.140^{* *}$ & $0.146^{* *}$ \\
& $(0.056)$ & $(0.054)$ & $(0.067)$ & $(0.064)$ \\
Density & -0.073 & -0.061 & -0.078 & -0.085 \\
& $(0.125)$ & $(0.124)$ & $(0.134)$ & $(0.131)$ \\
Graduate & 0.633 & 0.502 & 0.691 & 0.764 \\
& $(2.802)$ & $(2.786)$ & $(2.793)$ & $(2.800)$ \\
Highways & -0.048 & -0.059 & -0.043 & -0.036 \\
& $(0.210)$ & $(0.206)$ & $(0.216)$ & $(0.217)$ \\
Airports & -0.002 & -0.002 & -0.002 & -0.002 \\
& $(0.021)$ & $(0.020)$ & $(0.021)$ & $(0.021)$ \\
Observations & & & & \\
R-squared & 1,133 & 1,133 & 1,133 & 1,133 \\
FEs (Gravity) & 0.244 & 0.255 & 0.238 & 0.231 \\
FE Estimation & $\mathrm{No}$ & $\mathrm{jt}$ & $\mathrm{jt} ; \mathrm{i}$ & $\mathrm{it} ; \mathrm{jt}$ \\
KP-test & $\mathrm{t}, \mathrm{i}$ & $\mathrm{t}, \mathrm{i}$ & $\mathrm{t}, \mathrm{i}$ & $\mathrm{t}, \mathrm{i}$ \\
Hansen J (p-value) & 36.30 & 40.91 & 36.38 & 33.97 \\
& 0.108 & 0.122 & 0.102 & 0.742 \\
\hline
\end{tabular}

Standard errors (in parenthesis) are robust to heteroscedasticity and arbitrary autocorrelation $* * * \mathrm{p}<0.01$, ${ }^{* *} \mathrm{p}<0.05,{ }^{*} \mathrm{p}<0.1$. ln Migr /Pop instrumented using gravity prediction - Equation (13), estimated using OLS - and the Policy instrument; constant not reported.

Table 14 reports the estimates when the dependent variable is no longer the ratio of value added, but the log of value added in levels for the simple-task intensive sector - i.e. manufacturing - in column (1), the complex-task intensive sector - i.e. the restricted definition of services of our paper - in column (2), financial services only in column (3) and the retail sector alone in column (4). The results confirm the positive effect of migration on the simpletask sector and the insignificant effect on the different definitions of complex-task sector. Hence, the Rybczynski effect is due to the positive effect on the numerator without any negative effect on the complex-task sector.

Finally, Tables 15 and 16 presents the results of the same estimation as in Tables 13 and 14 but only with the gravity instrument and excluding the policy instrument. Also in this case, the results are generally confirmed. 
Table 14: 2SLS Estimation, Dependent Variables are Value Added in Levels

\begin{tabular}{|c|c|c|c|c|}
\hline Dep. Var: & $\begin{array}{c}(1) \\
\ln \left(V A_{m}\right)\end{array}$ & $\begin{array}{c}(2) \\
\ln \left(V A_{s}\right)\end{array}$ & $\begin{array}{c}(3) \\
\ln \left(V A_{f}\right)\end{array}$ & $\begin{array}{c}(4) \\
\ln \left(V A_{r}\right)\end{array}$ \\
\hline $\ln M i g r / P o p$ & $\begin{array}{c}0.117^{* *} \\
(0.051)\end{array}$ & $\begin{array}{c}-0.039^{*} \\
(0.023)\end{array}$ & $\begin{array}{c}-0.037 \\
(0.031)\end{array}$ & $\begin{array}{c}-0.044 \\
(0.027)\end{array}$ \\
\hline Density & $\begin{array}{c}0.071 \\
(0.118)\end{array}$ & $\begin{array}{c}0.168^{* *} \\
(0.083)\end{array}$ & $\begin{array}{c}0.311^{* *} \\
(0.126)\end{array}$ & $\begin{array}{l}-0.010 \\
(0.083)\end{array}$ \\
\hline Graduate & $\begin{array}{l}-0.061 \\
(2.299)\end{array}$ & $\begin{array}{l}-0.955 \\
(1.782)\end{array}$ & $\begin{array}{c}3.055 \\
(1.896)\end{array}$ & $\begin{array}{c}-6.039^{* * *} \\
(2.271)\end{array}$ \\
\hline Highways & $\begin{array}{c}-0.229^{* *} \\
(0.111)\end{array}$ & $\begin{array}{l}-0.204 \\
(0.160)\end{array}$ & $\begin{array}{l}-0.176 \\
(0.112)\end{array}$ & $\begin{array}{l}-0.233 \\
(0.227)\end{array}$ \\
\hline Airports & $\begin{array}{l}-0.001 \\
(0.012)\end{array}$ & $\begin{array}{c}0.001 \\
(0.012)\end{array}$ & $\begin{array}{c}0.003 \\
(0.010)\end{array}$ & $\begin{array}{c}0.001 \\
(0.014)\end{array}$ \\
\hline Observa & 1,133 & 1,133 & 1,133 & 1,133 \\
\hline R-squared & 0.678 & 0.927 & 0.944 & 0.795 \\
\hline FEs & $\mathrm{t} ; \mathrm{i}$ & $\mathrm{t} ; \mathrm{i}$ & $\mathrm{t} ; \mathrm{i}$ & $\mathrm{t} ; \mathrm{i}$ \\
\hline KP-test & 36.37 & 36.37 & 36.37 & 36.37 \\
\hline Hansen J (p-value) & 0.0345 & 0.439 & 0.190 & 0.953 \\
\hline
\end{tabular}

Standard errors (in parenthesis) are robust to heteroscedasticity and arbitrary autocorrelation $* * * \mathrm{p}<0.01$, ${ }^{* *} \mathrm{p}<0.05,{ }^{*} \mathrm{p}<0.1$. Dependent variables: $V A_{s}$ services value added excluding personal services; $V A_{f}$ financial services value added; $V A_{r}$ retail sector value added. $\ln M i g r / P o p$ instrumented using gravity prediction - Equation (13), estimated using OLS - and the Policy instrument; constant not reported.

Table 15: 2SLS Estimation, Province Fixed Effects (1st-Stage Gravity Estimated by PPML)

\begin{tabular}{lcccc}
\hline & $(1)$ & $(2)$ & $(3)$ & $(4)$ \\
Dep. Var: & \multicolumn{4}{c}{$\ln \left(V A_{\text {man }} / V A_{\text {serv }}\right)$} \\
\hline ln Migr/Pop & $0.179^{* *}$ & $0.162^{* *}$ & $0.149^{* *}$ & $0.150^{* *}$ \\
& $(0.076)$ & $(0.071)$ & $(0.069)$ & $(0.069)$ \\
Density & -0.122 & -0.103 & -0.088 & -0.089 \\
& $(0.144)$ & $(0.140)$ & $(0.136)$ & $(0.136)$ \\
Graduate & 1.165 & 0.963 & 0.800 & 0.808 \\
& $(2.828)$ & $(2.790)$ & $(2.799)$ & $(2.800)$ \\
Highways & -0.001 & -0.019 & -0.033 & -0.032 \\
& $(0.234)$ & $(0.227)$ & $(0.220)$ & $(0.220)$ \\
Airports & -0.002 & -0.002 & -0.002 & -0.002 \\
& $(0.023)$ & $(0.022)$ & $(0.021)$ & $(0.021)$ \\
& & & & \\
Observations & 1,133 & 1,133 & 1,133 & 1,133 \\
FEs (Gravity) & No & jt & jt ; i & it ; jt \\
FE Estimation & $\mathrm{t}, \mathrm{i}$ & $\mathrm{t}, \mathrm{i}$ & $\mathrm{t}, \mathrm{i}$ & $\mathrm{t}, \mathrm{i}$ \\
KP-test & 47.71 & 54.33 & 63.75 & 63.92 \\
\hline
\end{tabular}

Standard errors (in parenthesis) are robust to heteroscedasticity and arbitrary autocorrelation $* * * \mathrm{p}<0.01$, ${ }^{* *} \mathrm{p}<0.05,{ }^{*} \mathrm{p}<0.1$. InMigr $/$ Pop instrumented using gravity prediction (Equation 13, estimated using OLS), constant not reported. 
Table 16: 2SLS Estimation, Dependent Variables are Value Added in Levels

\begin{tabular}{lcccc}
\hline & $(1)$ & $(2)$ & $(3)$ & $(4)$ \\
Dep. Var: & $\ln \left(V A_{m}\right)$ & $\ln \left(V A_{s}\right)$ & $\ln \left(V A_{f}\right)$ & $\ln \left(V A_{r}\right)$ \\
\hline \multirow{3}{*}{$\ln$ Migr/Pop } & $0.182^{* *}$ & -0.051 & -0.061 & -0.043 \\
& $(0.074)$ & $(0.033)$ & $(0.045)$ & $(0.036)$ \\
Density & -0.001 & $0.180^{*}$ & $0.337^{* *}$ & -0.011 \\
& $(0.130)$ & $(0.092)$ & $(0.142)$ & $(0.088)$ \\
Graduate & 0.725 & -1.094 & 2.767 & $-6.026^{* * *}$ \\
& $(2.387)$ & $(1.809)$ & $(1.941)$ & $(2.300)$ \\
Highways & -0.161 & -0.216 & -0.201 & -0.232 \\
& $(0.140)$ & $(0.167)$ & $(0.127)$ & $(0.228)$ \\
Airports & -0.001 & 0.001 & 0.003 & 0.001 \\
& $(0.014)$ & $(0.012)$ & $(0.011)$ & $(0.014)$ \\
Observations & 1,133 & 1,133 & 1,133 & 1,133 \\
FEs & $\mathrm{t} ; \mathrm{i}$ & $\mathrm{t} ; \mathrm{i}$ & $\mathrm{t} ; \mathrm{i}$ & $\mathrm{t} ; \mathrm{i}$ \\
KP-test & 40.33 & 40.33 & 40.33 & 40.33 \\
\hline
\end{tabular}

Standard errors (in parenthesis) are robust to heteroscedasticity and arbitrary autocorrelation $* * * \mathrm{p}<0.01$, ${ }^{* *} \mathrm{p}<0.05,{ }^{*} \mathrm{p}<0.1$. Dependent variables: $V A_{s}$ services value added excluding personal services; $V A_{f}$ financial services value added; $V A_{r}$ retail sector value added. lnMigr/Pop instrumented using gravity prediction (Equation 13 , estimated using OLS), constant not reported. 


\section{F Evidence on Wage Ratio}

Relative wages of Manufacturing over Services are computed by province $i$, year $t$ and type of job $s$ (i.e. white collars vs blue collars). The two broad industry classification are the same used in the above regressions, Manufacturing (excluding Construction) and Services (Excluding Personal Serv.). The dependent variable is the log of the relative (Manufactures over Services) average weekly salary: yearly salary divided by the number of weeks by each worker; the tails of the individual wage distribution are trimmed $-1^{s t}-99^{\text {th }}$ percentile - to controls for outliers. To test for significant changes in the relative wage distribution over time, we regress the manufactures over services wage ratio on a set of year dummies.

Results are reported in 17 and confirm that relative wages are remarkably sticky over time and across Italian Provinces. Year dummies are never statistically significants, either if relative wages are expressed in levels (columns 1 and 2) or in growth rates (columns 3 and 4); results do not change if we include province by job fixed effects - columns 2 and 4 -i.e. considering only the intra-individual over time variability.

The data have been available through the research partnership between ISFOL and the Dipartimento di Scienze Sociali ed Economiche (Sapienza University of Rome). We thank Paolo Naticchioni for providing help along the lines of the research partnership. 
Table 17: Relative Wages: Province Level Evidence (1995-2002)

\begin{tabular}{|c|c|c|c|c|}
\hline \multirow[b]{2}{*}{ Dep. Var: } & \multicolumn{2}{|c|}{$(1) \quad(2)$} & \multicolumn{2}{|c|}{$(3) \quad(4)$} \\
\hline & \multicolumn{2}{|c|}{$\ln \left(W a g e_{j t s}^{\operatorname{man}} / W a g e_{i t s}^{s e r v}\right)$} & \multicolumn{2}{|c|}{$\Delta \ln \left(\right.$ Wage $\left.e_{j t s}^{\operatorname{man}} / W a g e_{i t s}^{s e r v}\right)$} \\
\hline \multirow[t]{2}{*}{ year $==1997$} & 0.002 & 0.006 & -0.008 & -0.003 \\
\hline & $(0.009)$ & $(0.008)$ & $(0.014)$ & $(0.014)$ \\
\hline \multirow[t]{2}{*}{ year $==1998$} & 0.006 & 0.006 & -0.012 & -0.013 \\
\hline & $(0.010)$ & $(0.010)$ & $(0.013)$ & $(0.013)$ \\
\hline \multirow[t]{2}{*}{ year $==1999$} & 0.014 & 0.016 & 0.004 & 0.004 \\
\hline & $(0.011)$ & $(0.010)$ & $(0.014)$ & $(0.014)$ \\
\hline \multirow[t]{2}{*}{ year $==2000$} & 0.009 & 0.015 & -0.006 & -0.011 \\
\hline & $(0.011)$ & $(0.011)$ & $(0.012)$ & $(0.012)$ \\
\hline \multirow[t]{2}{*}{ year $==2001$} & 0.003 & 0.005 & $-0.022^{*}$ & $-0.031^{* *}$ \\
\hline & $(0.011)$ & $(0.010)$ & $(0.013)$ & $(0.013)$ \\
\hline \multirow[t]{2}{*}{ year $==2002$} & 0.008 & 0.007 & -0.008 & -0.009 \\
\hline & $(0.011)$ & $(0.011)$ & $(0.012)$ & $(0.012)$ \\
\hline Observations & 5,684 & 5,684 & 4,564 & 4,564 \\
\hline R-squared & 0.120 & 0.001 & 0.005 & 0.002 \\
\hline $\mathrm{FE}$ & No & is & No & is \\
\hline T-test for Years (p-value) & 0.88 & 0.81 & 0.45 & 0.12 \\
\hline
\end{tabular}

Standard errors (in parenthesis) are clustered by Province and qualification level ${ }^{* * *} \mathrm{p}<0.01,{ }^{* *} \mathrm{p}<0.05$, $* \mathrm{p}<0.1$. All regressions include a constant not reported, year dummies may be interpreted as deviation from the reference period 1995-1996. 